\title{
Path integration from optic flow and body senses in a homing task
}

\author{
Melissa J Kearns, William H Warren, Andrew P Duchon, Michael J Tarr \\ Cognitive and Linguistic Sciences Department, Brown University, Box 1978, Providence, RI 02906, \\ USA; e-mail: Melissa_Kearns@brown.edu \\ Received 10 January 2001, in revised form 5 August 2001
}

\begin{abstract}
We examined the roles of information from optic flow and body senses (eg vestibular and proprioceptive information) for path integration, using a triangle completion task in a virtual environment. In two experiments, the contribution of optic flow was isolated by using a joystick control. Five circular arenas were used for testing: (B) both floor and wall texture; (F) floor texture only, reducing information for rotation; (W) wall texture only, reducing information for translation; (N) a no texture control condition; and (P) an array of posts. The results indicate that humans can use optic flow for path integration and are differentially influenced by rotational and translational flow. In a third experiment, participants actively walked in arenas B, F, and N, so body senses were also available. Performance shifted from a pattern of underturning to overturning and exhibited decreased variability, similar responses with and without optic flow, and no attrition. The results indicate that path integration can be performed by integrating optic flow, but when information from body senses is available it appears to dominate.
\end{abstract}

\section{Introduction}

Navigation is an important survival ability for many mobile animals. In foraging for food, for example, animals must be able to explore new territory and find their way back home, a task known as homing. Once a reliable food site has been found, they must be able to return to that location, and over time learn the layout of a number of such places in the surrounding environment. Such activities depend on possessing one or more navigational strategies.

In principle, strategies for navigation might involve path integration to keep track of one's current position relative to a home location, following a previously learned sequence of turns on a route, recognizing landmarks or vistas along a route or near a goal, or some form of spatial survey knowledge. Path integration, as defined by Loomis et al (1999) is a navigation strategy in which information about one's velocity or acceleration is integrated on-line to estimate the distance traveled and angles turned from a starting point, a form of biological odometry. This could be used to continuously update one's current position, or alternatively to update a 'homing vector' that specifies the current direction and distance to the starting point, thus providing a basic homing strategy.

Path integration may also have larger significance as a platform for acquiring other types of navigational knowledge. For example, to learn a route home based on a sequence of turns or landmarks, an animal must first be able to get back homeperhaps by means of path integration (Collett et al 1999). Similarly, path integration could enable one to learn routes between other places, and eventually to link them together in a graph-like form of spatial knowledge. Furthermore, odometry derived from path integration may allow one to build up survey knowledge with some metric structure, such as approximate distances and angles between places, which would enable the creation of new routes and short cuts between known places. In short, keeping track of where one is by means of path integration may provide a fundamental basis for learning the layout of the environment. 
In this paper, we investigate the information involved in human path integration during walking, using a simple homing task. Specifically, we examine the relative contributions of visual information on the one hand, and vestibular, proprioceptive, and efferent information on the other, which we collectively refer to as the body senses. Visual information about the distance and angle traveled is available in optic flow, the pattern of motion produced when an observer moves through a stationary environment (Gibson 1950). During observer rotation, the rate of optic flow from the surround uniquely specifies the angular speed as well as the direction of rotation (Warren 1995). Consequently, integrating the optic flow over time determines the absolute angle through which the observer has turned. For observer translation, the radial pattern of optic flow from the surround uniquely specifies the direction of translation, and the rate of optic flow from the ground specifies the speed of observer translation (eg in units of eye height per second). Integrating the optic flow over time determines the distance that the observer has traveled over the ground plane (eg in units of eye height). As long as eye height remains constant, so that a given amount of optic flow corresponds to the same distance traveled, homing can be successfully performed by integrating the optic flow. The same holds true for optic flow or motion parallax from the surround if the distances to lateral surfaces and objects remain stochastically similar over the whole path, as in a forest of constant density.

Information about distances and angles traveled by a walking observer is also available via the body senses. For example, vestibular information specifies the rotational and linear acceleration of the head, and double-integrating this signal recovers the angle of rotation and distance of translation (Berthoz et al 1995; Israël et al 1993; Ivanenko et al 1997). (Indeed, this is the principle by which the inertial head-tracking system in our laboratory operates.) Proprioception from receptors in muscles, tendons, joints, and cutaneous tissue may provide information about angles and distances traversed in terms of joint rotation, step lengths, or inertial forces. In theory, efferent signals about these intended movements may also be available. In our first two experiments, we tested the utility of optic flow for path integration by having subjects perform a homing task in a virtual environment using a joystick; (1) in this case, the body senses provided conflicting information that the observer was stationary. In a third experiment, we examined the combined contributions of visual and body senses during active walking in the virtual environment.

Much research has been done on path integration strategies in animals and humans. The object of these studies has been to determine which sources of information (visual, motor, etc) are used and the level of accuracy they provide for the task. In the animal literature, research has focused on insects such as bees and ants, whose navigation systems are highly developed in relation to the size of their nervous systems. For instance, bees have a highly accurate system for determining distances traveled from optic flow. Studies have shown that bees can reproduce the distance from the hive to a food site by integrating optic flow over the duration of a flight, primarily from lateral surfaces (Esch and Burns 1996; Srinivasan et al 1996, 1997).

Desert ants, which live in a fairly featureless environment, need to update their homing vector when foraging for food. It appears that they also take advantage of optic flow information and, to a lesser degree, motor information, in order to perform path integration, updating a very accurate homing vector (Ronacher and Wehner 1995). Other studies also support this theory, as evidenced by the fact that ants displaced even small distances from home are completely lost unless they have actively traveled the distance themselves (Gallistel 1990). 


\subsection{Human distance and turn estimation}

In order for an observer to return to a home location, he or she needs to know two values: the distance and the direction (orientation) to home. These two components have been studied separately in the human navigation literature. In previous studies these skills were tested with information from visual, proprioceptive, and vestibular information in isolation or in various combinations.

Thomson $(1980,1983)$ initiated research on updating position based on the body senses. He performed several studies in which participants walked blindfolded to a target location whose distance had been visually estimated. From these studies, Thompson proposed that non-visual navigation was accurate for short periods of time, but decayed rapidly when longer periods of time elapsed. He argued that only intermittent visual updating is necessary for accurate performance, showing a breakdown in accuracy when traveling longer distances, or when traveling shorter distances if the participant is delayed prior to response. However, his proposal of a temporal decay was not replicated by others (Elliott 1986; Steenhuis and Goodale 1988), who found that accuracy for blind walking is simply reduced as a function of distance traveled. These results suggest that humans can rely on the body senses to update observer position and match a visually perceived distance.

A study comparing normal and labyrinthine-defective subjects (Glasauer et al 1994) showed similar performance for walking to a previously seen target by both groups, suggesting that vestibular information is not necessary for this task. On the other hand, Berthoz et al (1995) found that blindfolded people perform relatively accurately when retracing distances traversed in a passive sled if the velocity profile is simple, indicating that vestibular information can be used for determining linear movements. Task differences also appear to influence performance. A study by Israël et al (1993) revealed underestimation of distance to visual targets on an outbound path, while distance estimation accuracy improved on a return path. Bremmer and Lappe (1999) found that participants can accurately discriminate visual displays of distances traversed even when they are in different directions (forward versus backward perceived selfmotion). In addition, when participants, using a manual control device, were asked to reproduce a visual distance presented on a display (either a linear, sinusoidal, or complex path) distance estimates were highly accurate with visual feedback, but tended to be overestimated without it.

For rotation and orientation, it appears that accurate updating is dependent on the body senses during physical movement. Studies by Rieser (1989; Rieser et al 1986) have shown that people are much better at identifying (fixed) object locations from a new orientation if they physically walked or turned to the new orientation than if they imagined the same movement. This is true regardless of whether the locations were learned visually or blindfolded. Continuously pointing at (tracking) the home location during outbound motion appears to improve orientation estimates in a blindfolded passive movement task (Ivanenko et al 1997). In a virtual maze environment, it was found that performance for identifying the direction of objects relative to a fixed testing location was best when participants were allowed full physical movement while learning (Chance et al 1998).

Studies by Bakker et al (1999) examined the roles of both the body senses and visual information in reproducing turns. The most accurate rotations were produced when participants physically turned through the desired angle, regardless of whether this was coupled with visual information in a head mounted display. In all conditions, the general pattern was that participants increasingly undershot the target as turn angle increased. Interestingly, decreasing the optic flow rate by increasing the geometrical field of view (FOV) ('zooming' the display, which leaves the edge rates constant) reduced the amount of undershooting during active body movement, but did not 
alter the pattern of increased undershooting with larger turn angles. With vision alone, on the other hand, this pattern reversed and participants increasingly overshot the angles to be turned, consistent with reliance on optic flow rate. However, there were no effects of changing the visual gain when proprioceptive and vestibular information was available. Without vision, estimations of rotation improve when the task is to return to the original orientation, compared with replicating the angle in a direction away from the starting point (Israël et al 1995). In sum, the body senses appear sufficient for updating distance and orientation, at least when tested in isolation. However, the role of visual information has not been adequately studied.

\subsection{Triangle completion: combined distance and turn estimation}

The simplest situation that combines distance and orientation information is a trianglecompletion task. It is a paradigm commonly used to examine path integration abilities for homing, and is used in the current study. As seen in figure 1, the subject starts at a 'home' location, moves along two fixed legs and then is asked to respond by finding the most direct route home, which is the third leg of the triangle. This task (and others that require updating of orientation and distance from a place) has been used to study the roles of vestibular and proprioceptive information and, separately, the role of visual information in path integration, but there is no work in which their relative contributions in a homing task have been examined.

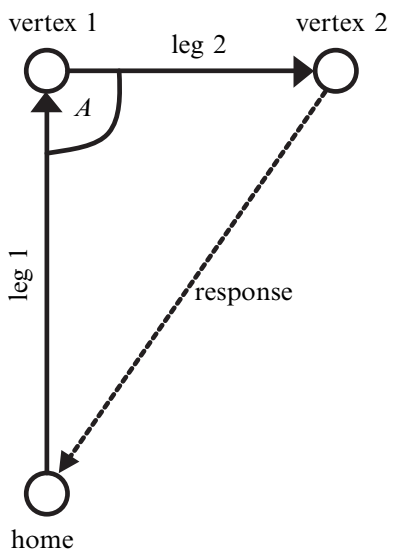

Figure 1. Triangle-completion task. First two legs are fixed, third leg is response.

The majority of the work on path integration for homing has focused on non-visual conditions (Loomis et al 1993; Sholl 1989; for a good review of the literature, see Klatzky et al 1997). Experiments typically involve guided walking of a blindfolded individual for the outbound legs, requiring the participant to actively turn and walk back home by the most direct path. In this situation, participants have access to vestibular and proprioceptive information on the outbound path. The general conclusions are that performance is reasonably accurate, but responses tend to be stereotyped; observers are only somewhat sensitive to differences in the outbound leg lengths and the turn angle. This is exhibited by underestimation of large angles and lengths and overestimation of smaller angles and shorter outbound paths. When only vestibular information was available on the outbound path (participants were pushed in a wheelchair), Sholl (1989) saw poor performance for pointing back to the origin. Although this is a weak form of vestibular stimulation, it suggests that a minimal combination of proprioceptive and vestibular information from physical walking may be required to perform path integration with any degree of accuracy.

Some recent path-integration research dealt with the role of visual flow information (Péruch et al 1997; Riecke et al 2000). These experiments have typically used virtual 
environments and joystick control in a triangle-completion task, which also provides some minimal efference from active joystick control. Using a flat projection screen, Péruch et al (1997) found that homing with visual information alone was somewhat less accurate than the performance reported with body senses alone by Loomis et al (1993) for blindfolded walking. Although Péruch et al (1997) also found stereotyped responses, their data differed from those of Loomis et al (1993) in that the final turn angle was consistently underestimated. This underestimation was more apparent with the longest distances and largest turn angles in the outbound path.

It is important to note that the visual environment in Péruch et al's study contained no textured surfaces, and hence minimal optic flow. The display included two cylindrical targets inside a ring of evenly spaced, solid colored cylinders that rested on a solid colored ground plane. Owing to the large size of the triangles (outbound legs of 20 and $9-27 \mathrm{~m}$ ) relative to the bounding ring of cylinders (radius $27 \mathrm{~m}$ ), self-motion information was available from the expansion of these cylinders, the change in their angle of elevation, and motion parallax between the triangle targets and the outer ring. Strategies using the relationship of the perceiver to the targets, which remained visible, were emphasized in the second experiment. In this case, the procedure required the participant, upon reaching the second target, to turn and face the first target again before turning back to face the starting location. This procedure change led to more accurate performance, although still not as accurate as that found by Loomis et al (1993). The authors concluded that visual information alone led to greater under-turning than the body senses alone.

Riecke et al (2000) did a similar set of experiments and obtained greater accuracy for turning responses, but the same pattern of increased undershooting at larger distances for translation, as Loomis et al (1993), Péruch et al (1997), and Sholl (1989). They tested participants on a larger set of triangles, and several environments, including a random-blob textured environment and a detailed 'town' without stable landmarks. Nonetheless, the accurate turn results are surprising, since they run contrary to previous data. One explanation is that, in contrast to all other triangle-completion experiments, participants were given training with feedback, including a simultaneous bird's-eye view of the triangle and the participant's path through the environment, as well as accuracy feedback at the end of each training trial. With such training, the study does not assess the normal state of the path-integration system, and it is not surprising that the results are more accurate than earlier data.

\subsection{Objectives}

In sum, the role of visual information in path integration has not been adequately assessed in previous research, specifically whether optic flow is normally integrated to estimate distances and angles during homing. In addition, the roles of visual information and the body senses, in estimating both distances and angles, have not been compared in the same experimental setup. The aim of the present study has been to investigate path integration from optic flow and the body senses, both alone and in combination, using a triangle-completion task. By manipulating these sources of information, we hoped to answer the following questions: Can path integration be performed from optic flow alone, without specific training? If so, does optic flow information about translation and rotation differentially affect performance on distances and angles traversed? What are the relative contributions of information from optic flow and body senses?

We investigated these questions in a unique virtual-environment navigation laboratory (VENLab). The VENLab allows a participant wearing a head mounted display (HMD) to walk freely in a large open space while head movements are accurately tracked. This setup enables us to manipulate the visual information available during either 
joystick control or active walking. The present experiments improved upon previous methods in the following ways. First, texture-mapped environments provided more optic flow than that of Péruch et al (1997). Second, we reduced other sources of visual information that may have been present in Péruch et al's (1997) environment. Third, we provided no training or feedback, in contrast to Riecke et al (2000), minimizing the possibility of learning specific strategies. Finally, we compared tests of optic flow and the body senses separately and in combination in the same virtual environment.

\section{General methods}

\subsection{The VENLab}

The VENLab is a $12 \mathrm{~m} \times 12 \mathrm{~m}$ room with a tracking system mounted in the ceiling, a tethered HMD, and a graphics workstation. Virtual environments are generated on a Silicon Graphics (SGI) Onyx2 with an Infinite Reality Engine, using Sense8's World Tool Kit software. These worlds are then displayed in the HMD (Kaiser Electro-optics Proview 80) at a frame rate of $60 \mathrm{~Hz}$. The HMD is a fully immersive stereoscopic display with a resolution of $640 \times 480$ pixels in each VGA channel and a 60 deg horizontal by $40 \mathrm{deg}$ vertical FOV. An isolation shield is placed over the lenses to block out outside light and visual information.

The VENLab interfaces include a Joystick Controller and an Intersense Tracking System. These provide a combination of control options for the examination of navigation questions with vision and/or active walking. For experiments 1 and 2, the HMD and joystick were used without the tracking system, and for experiment 3, the tracking system was used with the HMD to update head position.

The joystick (ThrustMaster serial port) allows full $360^{\circ}$ movement with software adjustable control for translation and rotation. For the current experiments, joystick position was mapped to observer velocity, with a dead zone that restricted the central $15 \%$ of the joystick translational range and central $20 \%$ of the joystick rotational range. Maximum translation speed was set at $2.1 \mathrm{~m} \mathrm{~s}^{-1}$, with smooth acceleration from zero upon exiting the dead zone. Rotation speed was fixed at $30^{\circ} \mathrm{s}^{-1}$ once joystick movement was outside of the central dead zone. From pilot testing with the displays, it was determined that this combination was comfortable for the majority of participants, providing a balance of sensitivity and speed given the physical resistance of the joystick. The latency between joystick motion and display update was at most two frames $(\sim 30 \mathrm{~ms})$.

The tracking system (Intersense IS-900) is a hybrid acousto-inertial six-degrees-offreedom tracking system. It tracks head orientation and position by integrating the outputs of its gyroscopes and accelerometers, and corrects drift by using a roomreferenced ultrasonic time-of-flight range measuring system. The system detects the precise position and orientation of a person in the room and updates the HMD graphics for this viewpoint. One hundred and eighty-one ultrasonic emitters are mounted on the ceiling and three microphones plus an inertial system are fixed on top of the HMD. This system allows a person to move freely within the $12 \mathrm{~m}^{2}$ tracking area, with a measured display latency of at most three frames $(\sim 50 \mathrm{~ms})$.

\subsection{Displays}

The virtual environment used in the present experiments was a circular arena $(36 \mathrm{~m}$ radius) with a floor and a circular wall (3.3 $\mathrm{m}$ high) bounding the space. The high wall insured that the top extended above the HMD's FOV from anywhere in the arena, when looking straight ahead. The large radius insured that optic flow from the wall provided minimal information about observer translation (eg time to contact). A multiscale random-texture pattern in blue to gray was on either the floor, walls, both, or neither, depending on the display condition (see figure 3). ${ }^{(2)}$

(2) Texture on the walls was at a larger scale than the texture on the floor. 


\subsection{The task}

The task was a basic triangle-completion paradigm. The participant began each trial in a fixed location in a homogeneously textured environment that was devoid of landmarks except for a red pole directly in front of the participant. This was the marker for the first vertex. All marker poles were $25 \mathrm{~cm}$ in radius with a sphere on top that was $50 \mathrm{~cm}$ in radius and adjusted so that the center of the sphere was at eye height. The participant moved forward along leg 1, directly to the red pole. Upon reaching the pole, the participant made contact with it and it disappeared with a popping sound. Next, the participant was instructed to turn to the right until a blue pole came into view. This marked the second vertex. The participant then traveled along leg 2 to the blue pole which disappeared after contact. At this point the participant was instructed to turn and face 'home' (the starting location) and travel directly to that point. In experiments 1 and 2, participants indicated they were at 'home' by pressing a joystick button. This advanced the participant to a blank screen (inter-trial interval). After pressing a second joystick button, the participant self-advanced to the next trial. In experiment 3, participants indicated they were 'home' verbally and the experimenter ended the trial. Then an inter-trial environment appeared with orienting poles so that the participant could be positioned properly in the physical room for the next trial. The experimenter then initiated the next trial.

\subsection{Participants}

Participants were undergraduate and graduate students at Brown University. The average age of the participants over all three experiments (including those who were unable to complete the experiment owing to simulator sickness) was 23.4 years. Participants were paid $\$ 6$ per hour for their participation.

\subsection{Procedure}

Prior to running an experiment, it was necessary to calibrate the HMD. Once the lenses were set for the individual's interocular distance, a random-dot stereogram display of a rectangle was presented to ensure that the participant could fuse the binocular images. If, after readjustments to the HMD, the participant could not fuse the image, the experiment was terminated and no payment was given. This happened only in one case.

Next, the HMD was removed so that the participant could fill out an informed consent form and two questionnaires. Participants then read instructions and the experimenter drew a diagram of the triangle task to clarify the directions.

A virtual-reality familiarization period preceded testing to allow the participant to get used to manipulating the joystick or walking in a virtual world while wearing the HMD, using a 'pacman' maze in which the participant collected floating cubes by making contact with them. Next, the participant had two or three practice trials with the triangle-completion task in the fully textured arena (figure 3c). Test trials followed immediately after the practice trials. Test trials were always blocked by arena condition, with three trials for each of six triangles randomly presented within each block.

After each block, the participant was prompted to take a break from the task and remove the HMD for a few minutes. Participants were also informed that they could take breaks in between trials as often as necessary. During all breaks, the experimenter informally assessed whether the participant was experiencing simulator sickness through observation and by asking general questions about his or her experience, to avoid suggestion. If the participant reported symptoms such as headache, nausea, feeling overheated, or sleepiness, the experiment was immediately terminated. No one reported feeling these symptoms for more than three hours after the experiment, and most reported a return to normal health within a half hour. Such symptoms arose only in the vision-only experiments (experiments 1 and 2), whereas in the active-walking 
experiment (experiment 3) everyone felt comfortable enough to complete the experiment. After the experiment, the participant completed two additional questionnaires.

\subsection{Analyses}

The subject's path on the third leg can be schematized as a response vector from vertex 2 to the subject's final position. This allows five response measures (see figure 2). (a) Position error was calculated by measuring the absolute distance from the final position to home. (b) Path length represents the distance actually traveled, corresponding to the length of the response vector. (c) Path length error is the error in the distance traveled, corresponding to the difference between the observed path length and the length of leg 3. The error is negative if the response undershoots the distance to home, and positive if it overshoots the correct distance. (d) Turn angle represents the turning response at vertex 3, computed as the internal angle between leg 2 and the response vector. (e) Angular error is the error in the turning response, computed as the difference between the correct interior angle and the observed turn angle. This error is negative if the response undershoots the correct turn, and positive if it overshoots the turn.

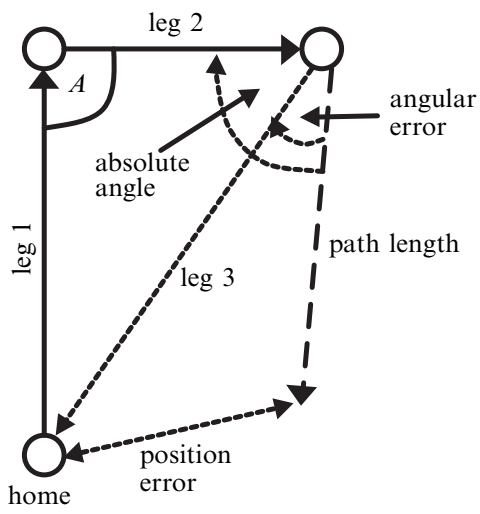

Figure 2. Absolute and error measures calculated from responses. Path length error is calculated as path length minus leg 3.

Analyses of variance (ANOVAs) were performed on the five response measures and also on the subject standard deviations of these measures. Linear dependent measures (position error, path length error, and path length) were analyzed with multivariate ANOVAs. Angular dependent measures (angular error and angle turned) were analyzed with multiple-sample Watson-Williams one-way ANOVAs for circular data (see Batschelet 1981). Owing to the limitations of this test, all two-way interactions were tested as separate one-way effects. Higher-order interactions were analyzed in the same manner, but were only tested if they proved significant for the linear measures. The Watson - Williams was the most robust statistic available.

\section{Experiment 1: Optic flow for translation and rotation}

Path integration requires two types of information to update the homing vector: the distance traveled on each leg and the angle turned at each intersection. As noted above, these two components are specified in the optic flow field. The distance traveled during translation can be determined by temporally integrating the rate of optic flow from the ground, assuming a constant eye height. The angle turned during rotation can be determined by temporally integrating the rate of optic flow from the surround. If observers use optic flow for path integration, one might thus expect specific effects of reducing the translational flow on path length and reducing the rotational flow on turn angle. Such effects would confirm a reliance on optic flow in a functionally specific manner.

Given that optic flow is generated by visible structure in the environment, we varied the translational and rotational components of flow by manipulating the texture 
in our circular arena. First, to reduce translational flow information about distance traveled in the arena, we removed the texture on the floor. Second, rotational flow from the walls of the arena is likely to provide more salient information about the angle turned than flow from the ground. This is because the velocity of flow is a sine function of its angle from the axis of observer rotation, and thus flow increases from the ground at the subject's feet to surfaces at eye level. Thus, to reduce rotational flow, we removed the texture on the walls of the arena. In experiment 1, we thus tested three arenas (figure 3), one with texture on the floor only (arena F), one with texture on the walls only (arena W), and one with both floor and wall texture (arena B).

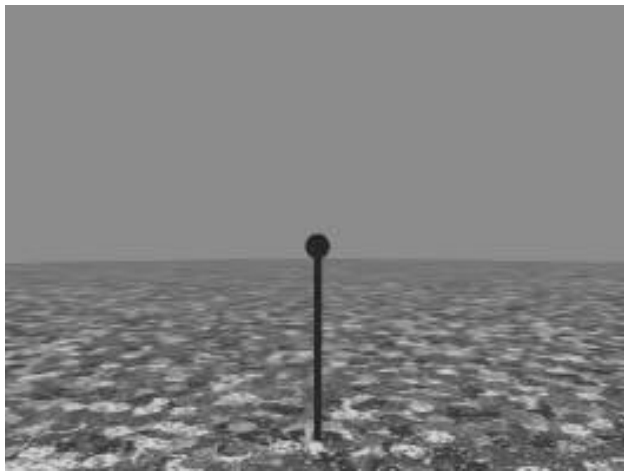

(a)

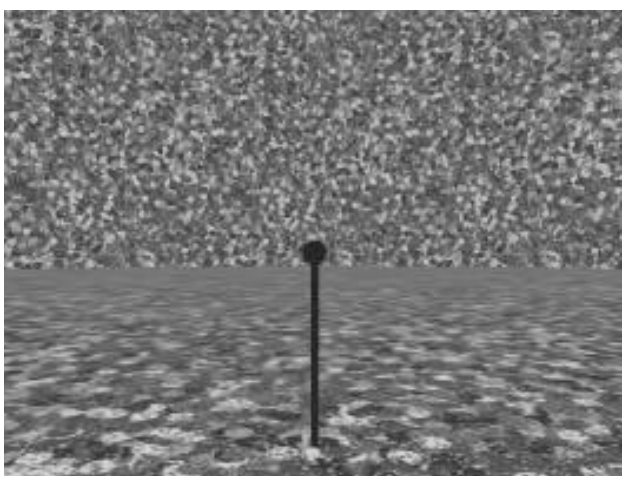

(c)

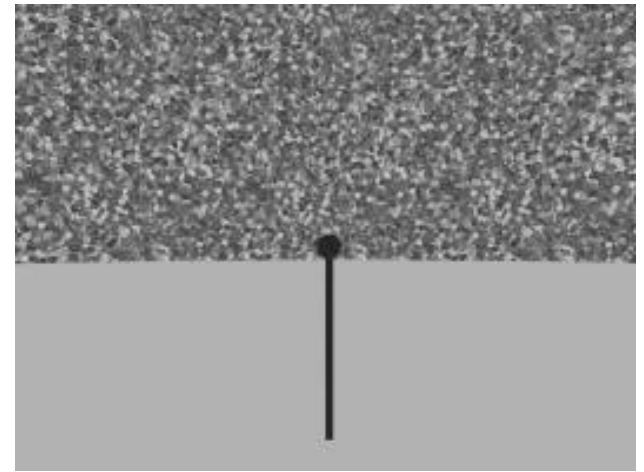

(b)

Figure 3. Arenas used for experiment 1 . (a) Arena $\mathrm{F}$ with floor texture only, (b) arena $\mathrm{W}$ with wall texture only, and (c) arena $\mathrm{B}$ with both floor wall and texture. Displays show the view from the home location prior to the start of a trial, including the view of the first (red) marker pole.

The arenas were sufficiently large that observer translation yielded minimal optic flow from the walls and minimal change in the elevation angle of the wall baseline. For example, the time-to-contact with the wall at $30 \mathrm{~m}$ with a normal walking speed is $30 \mathrm{~s}$; with the maximum joystick speed it is $15 \mathrm{~s}$. Perceptual judgments of time-tocontact from optic flow are essentially constant above $8 \mathrm{~s}$ (Schiff and Detwiler 1979; Schiff and Oldak 1990) suggesting that little effective information about translation toward the walls is obtained at such low flow rates. In addition, when approaching the wall from $35 \mathrm{~m}$ to $30 \mathrm{~m}$ away, corresponding to the longest leg of our triangles, the change in the angle of elevation of the floor is only $0.45^{\circ}$. Therefore, the information about translation offered by the wall is minimal, particularly in comparison to the information from the ground plane.

Three additional sources of information about the distance traveled on the outbound legs of the triangle were available during approach to the target poles at vertex A and vertex B: (i) time-to-contact, derived from the optical expansion of the pole; (ii) binocular disparity of the pole; and (iii) elevation angle of the base of the pole 
in the FOV. Thus, an observer might estimate the lengths of the two outbound legs from such information (no target poles were visible during the response leg). However, a control condition in experiment 2 will show that information from the poles alone yields markedly inaccurate performance.

Thus, the aim of the first two experiments was to test whether optic flow is sufficient for visual path integration. If so, we expect performance to be approximately as accurate as that found by Loomis et al (1993) for blindfolded walking with body senses alone. A secondary question is whether translational optic flow from the ground plane and rotational optic flow from the walls differentially contribute to path integration. If this is the case, we might expect to find increased path length errors when texture is removed from the floor (arena $\mathrm{W}$ ), and increased angular errors when texture is removed from the walls (arena F).

\subsection{Methods}

In experiments 1 and 2, participants wore the HMD while seated at a desk and controlled their movements with a joystick. Since movement of the head did not map to changes in the visual world, participants were reminded to keep their heads fixed.

3.1.1 Displays and triangles. Three arenas were used to manipulate the presence of optic flow (figure 3). Arena B included both wall and floor texture, arena $\mathrm{W}$ had wall texture only, and arena $\mathrm{F}$ had floor texture only. The six triangles tested were a subset of those used by Loomis et al (1993) in their blind walking studies and Péruch et al (1997) in their visual task experiments. These triangles all had a constant leg 1 length, but the length of leg 2 and the size of the interior angle (angle $A$ ) between the legs varied, as shown in table 1 (see also figure 4).

Table 1. Experiment 1. Triangle stimuli dimensions. Angle $A$ is the interior angle between Leg 1 and Leg 2 (see figure 1 for clarity).

\begin{tabular}{lllc}
\hline Triangle & Leg $1 / \mathrm{cm}$ & Leg $2 / \mathrm{cm}$ & Angle $A /^{\circ}$ \\
\hline $\mathrm{a}$ & 425 & 225 & 60 \\
$\mathrm{~b}$ & 425 & 225 & 90 \\
$\mathrm{c}$ & 425 & 225 & 120 \\
$\mathrm{~d}$ & 425 & 425 & 60 \\
$\mathrm{e}$ & 425 & 425 & 90 \\
$\mathrm{f}$ & 425 & 425 & 120 \\
\hline
\end{tabular}

3.1.2 Participants. Data from eleven participants-six men and five women-were analyzed. Five other women dropped out owing to simulator sickness, and three participants - two women and one man - were excluded from the analyses because they were extreme outliers. Mean outlier data were characterized by turns different from normative data by $90^{\circ}$ to $180^{\circ}$. Two of the participants made path length estimates that were longer than the normative data by $50 \%$ or more, and one had path length estimates that were less than half as long as the remaining participants. Given the qualitatively different responses of these three participants relative to the remaining eleven, including their data would have rendered the analyses uninformative about the dominant patterns of response. However, one must be cautious about generalizing the results to the population at large and bear in mind individual differences in navigation ability.

\subsection{Results and discussion}

The data appear in figure 4 in which graphical plots of each triangle are used. The responses for each arena are represented by a 95\% confidence ellipse, calculated from all the final response positions for all participants. There is a $95 \%$ probability that the population mean for that condition is contained within the ellipse. In addition, the means 


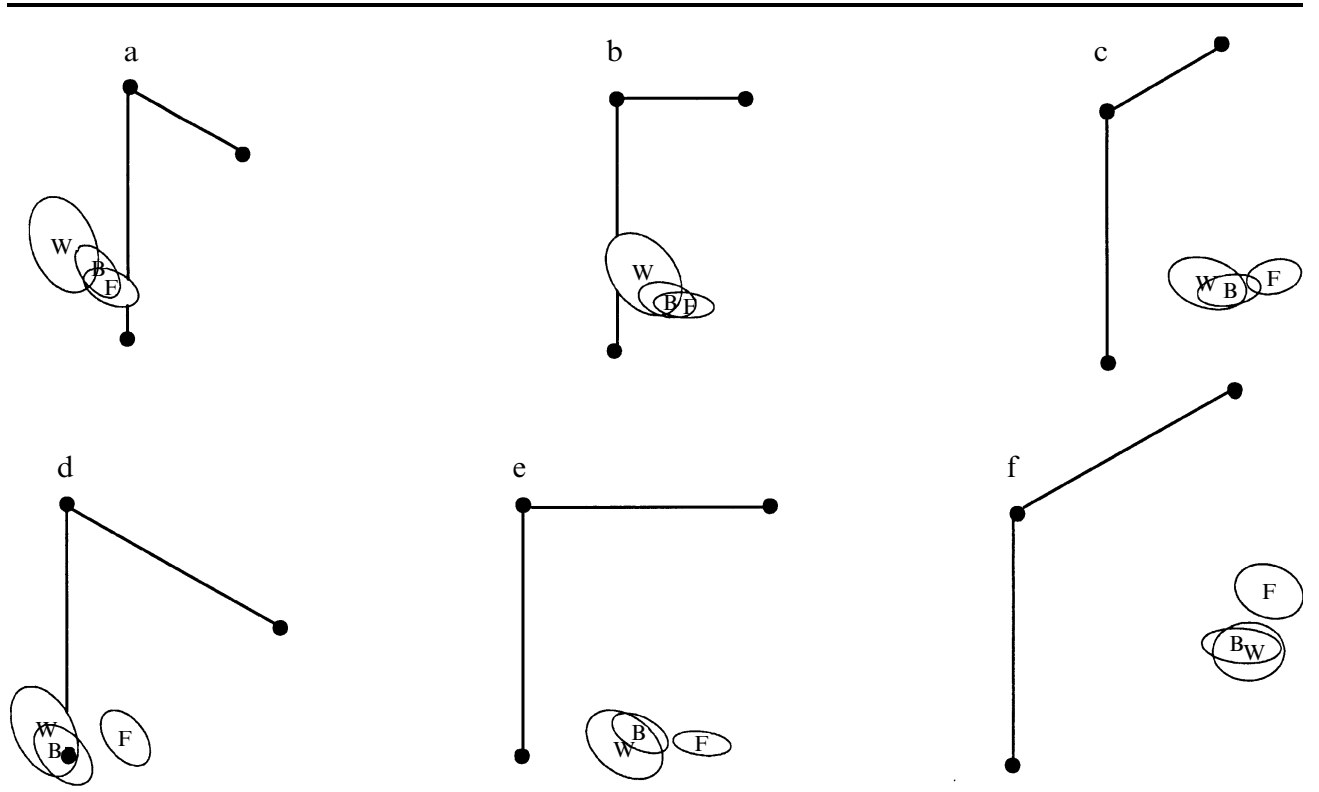

Figure 4. 95\% confidence ellipses of responses for each arena for all triangles in experiment 1 . Lines indicate outbound path of the triangle. Label in the center of the ellipse indicates the arena display condition and also marks the location of the population mean.

and standard deviations for each condition are presented in table 2. Path length measures were tested in mixed-design ANOVAs (Arena $\times$ Leg $2 \times$ Angle $A \times$ Trial $\times$ Gender), whereas angular dependent measures were analyzed with one-way circular WatsonWilliams tests for each independent variable. Significant differences were observed between the different arena conditions and triangle shapes, as well as between men and women. However, when looking at mean performance for triangle shape, the overall response pattern is comparable to that of Loomis et al (1993), indicating that visual information can be used for path integration, although body senses are somewhat more accurate (these differences in performance will be discussed later).

First consider the effects of arena. The circular one-way ANOVAs revealed significant differences in the angular measures (absolute angle, $F_{2,592}=5.42, p<0.01$; angular error, $F_{2,592}=4.49, p<0.05$ ). The tendency for participants to turn less in arena $\mathrm{F}$ than in either arena $\mathrm{B}$ or $\mathrm{W}$ is evident in figure 4. This demonstrates a differential effect of optic flow on rotation estimates, although the direction of this finding is somewhat surprising. It might be expected that a reduction in rotational flow with floor texture alone would cause participants to perceive that they had rotated through a smaller angle, leading them to turn more, rather than less (as in Bakker et al 1999). It is possible that the reduction of rotational flow in arena $F$ caused a degree of uncertainty about rotation, leading to more conservative responses. In any case, it is clear that a reduction in visual information for rotation did affect the participants' ability to estimate how far they had turned.

Additionally, analyses of the standard deviation of path length revealed that arena $\mathrm{W}$ distance responses were significantly more variable than those in arenas $\mathrm{B}$ and $\mathrm{F}$ as reflected in the standard deviation (SD) of path length error $\left(F_{2,18}=3.64, p<0.05\right)$ although no other linear measures were significant. The larger ellipses for arena $\mathrm{W}$ in figure 4 demonstrate this result graphically. This indicates that the removal of ground flow in arena $\mathrm{W}$ reduced the reliability of optic flow information for estimating distances traveled. It further suggests that optic flow contributes to path integration over and above whatever visual information was available from the marker poles. 
Table 2. Experiment 1. Means and standard deviations (in parentheses) for all conditions.

\begin{tabular}{|c|c|c|c|c|c|c|c|}
\hline & \multicolumn{7}{|c|}{ Triangle } \\
\hline & $\mathrm{a}$ & $\mathrm{b}$ & $\mathrm{c}$ & $\mathrm{d}$ & $\mathrm{e}$ & $\mathrm{f}$ & mean \\
\hline Correct length $/ \mathrm{cm}$ & 368 & 481 & 572 & 425 & 601 & 736 & 530.5 \\
\hline $\begin{array}{l}\text { Path length } / \mathrm{cm} \\
\text { arena } \mathrm{B}\end{array}$ & $\begin{array}{c}408.4 \\
(108.4)\end{array}$ & $\begin{array}{c}433.9 \\
(136.0)\end{array}$ & $\begin{array}{c}480.7 \\
(146.0)\end{array}$ & $\begin{array}{c}512.3 \\
(189.0)\end{array}$ & $\begin{array}{c}503.7 \\
(129.1)\end{array}$ & $\begin{array}{c}535.3 \\
(131.5)\end{array}$ & $\begin{array}{c}479.1 \\
(147.3)\end{array}$ \\
\hline arena $\mathrm{F}$ & $\begin{array}{c}405.8 \\
(109.8)\end{array}$ & $\begin{array}{c}435.5 \\
(121.8)\end{array}$ & $\begin{array}{c}456.6 \\
(156.2)\end{array}$ & $\begin{array}{c}411.8 \\
(160.6)\end{array}$ & $\begin{array}{c}474.9 \\
(115.8)\end{array}$ & $\begin{array}{c}477.1 \\
(120.8)\end{array}$ & $\begin{array}{c}443.6 \\
(133.7)\end{array}$ \\
\hline arena $\mathrm{W}$ & $\begin{array}{c}518.7 \\
(284.9)\end{array}$ & $\begin{array}{c}504.6 \\
(277.6)\end{array}$ & $\begin{array}{c}513.1 \\
(208.9)\end{array}$ & $\begin{array}{c}567.1 \\
(286.6)\end{array}$ & $\begin{array}{c}584.0 \\
(238.0)\end{array}$ & $\begin{array}{c}542.4 \\
(189.2)\end{array}$ & $\begin{array}{c}538.3 \\
(249.0)\end{array}$ \\
\hline mean & $\begin{array}{c}444.8 \\
(192.5)\end{array}$ & $\begin{array}{c}458.0 \\
(192.7)\end{array}$ & $\begin{array}{c}483.5 \\
(172.4)\end{array}$ & $\begin{array}{c}497.1 \\
(226.0)\end{array}$ & $\begin{array}{c}520.9 \\
(174.6)\end{array}$ & $\begin{array}{c}518.2 \\
(151.5)\end{array}$ & $\begin{array}{c}487.0 \\
(187.8)\end{array}$ \\
\hline Correct angle $/{ }^{\circ}$ & 88 & 62 & 40 & 60 & 45 & 30 & 54.2 \\
\hline $\begin{array}{l}\text { Absolute angle } /{ }^{\circ} \\
\text { arena } \mathrm{B}\end{array}$ & $\begin{array}{c}76.5 \\
(37.1)\end{array}$ & $\begin{array}{c}74.0 \\
(32.9)\end{array}$ & $\begin{array}{c}64.8 \\
(29.0)\end{array}$ & $\begin{array}{c}70.0 \\
(36.5)\end{array}$ & $\begin{array}{c}64.3 \\
(30.8)\end{array}$ & $\begin{array}{c}68.3 \\
(32.2)\end{array}$ & $\begin{array}{c}69.5 \\
(33.5)\end{array}$ \\
\hline arena $\mathrm{F}$ & $\begin{array}{c}83.8 \\
(38.1)\end{array}$ & $\begin{array}{c}80.9 \\
(34.8)\end{array}$ & $\begin{array}{l}76.0 \\
(27.5)\end{array}$ & $\begin{array}{c}77.9 \\
(40.5)\end{array}$ & $\begin{array}{l}80.1 \\
(28.5)\end{array}$ & $\begin{array}{c}76.7 \\
(32.3)\end{array}$ & $\begin{array}{c}79.2 \\
(34.0)\end{array}$ \\
\hline arena $\mathrm{W}$ & $\begin{array}{c}73.1 \\
(39.7)\end{array}$ & $\begin{array}{l}72.0 \\
(31.3)\end{array}$ & $\begin{array}{l}64.8 \\
(27.7)\end{array}$ & $\begin{array}{l}64.7 \\
(41.4)\end{array}$ & $\begin{array}{l}64.5 \\
(32.8)\end{array}$ & $\begin{array}{c}73.1 \\
(28.5)\end{array}$ & $\begin{array}{r}68.7 \\
(34.2)\end{array}$ \\
\hline mean & $\begin{array}{c}77.8 \\
(38.5)\end{array}$ & $\begin{array}{l}75.5 \\
(33.2)\end{array}$ & $\begin{array}{c}68.6 \\
(28.5)\end{array}$ & $\begin{array}{l}70.8 \\
(39.8)\end{array}$ & $\begin{array}{l}69.8 \\
(31.5)\end{array}$ & $\begin{array}{c}72.7 \\
(31.2)\end{array}$ & $\begin{array}{c}72.5 \\
(33.9)\end{array}$ \\
\hline $\begin{array}{l}\text { Position error/cm } \\
\text { arena B }\end{array}$ & $\begin{array}{c}256.4 \\
(180.4)\end{array}$ & $\begin{array}{c}277.2 \\
(130.0)\end{array}$ & $\begin{array}{c}334.9 \\
(180.4)\end{array}$ & $\begin{array}{c}298.0 \\
(176.5)\end{array}$ & $\begin{array}{c}323.2 \\
(145.8)\end{array}$ & $\begin{array}{c}504.5 \\
(261.8)\end{array}$ & $\begin{array}{c}332.3 \\
(199.0)\end{array}$ \\
\hline arena $\mathrm{F}$ & $\begin{array}{c}256.0 \\
(146.6)\end{array}$ & $\begin{array}{c}276.7 \\
(134.7)\end{array}$ & $\begin{array}{c}369.5 \\
(200.5)\end{array}$ & $\begin{array}{c}287.6 \\
(149.3)\end{array}$ & $\begin{array}{c}368.2 \\
(174.5)\end{array}$ & $\begin{array}{c}596.1 \\
(233.5)\end{array}$ & $\begin{array}{l}359.0 \\
(208.8)\end{array}$ \\
\hline arena $\mathrm{W}$ & $\begin{array}{c}387.9 \\
(356.0)\end{array}$ & $\begin{array}{c}387.1 \\
(294.0)\end{array}$ & $\begin{array}{c}384.2 \\
(224.2)\end{array}$ & $\begin{array}{c}382.3 \\
(270.9)\end{array}$ & $\begin{array}{c}424.9 \\
(179.1)\end{array}$ & $\begin{array}{c}543.8 \\
(221.4)\end{array}$ & $\begin{array}{c}418.4 \\
(267.0)\end{array}$ \\
\hline mean & $\begin{array}{c}300.1 \\
(250.8)\end{array}$ & $\begin{array}{l}313.6 \\
(205.9)\end{array}$ & $\begin{array}{c}362.8 \\
(201.5)\end{array}$ & $\begin{array}{l}322.6 \\
(207.9)\end{array}$ & $\begin{array}{c}372.1 \\
(170.6)\end{array}$ & $\begin{array}{c}548.1 \\
(240.0)\end{array}$ & $\begin{array}{r}369.9 \\
(229.4)\end{array}$ \\
\hline
\end{tabular}

Next, consider the effects of triangle shape. There were no significant effects of leg 2 or angle $A$ on the absolute measures, revealing that participants generally produced similar responses regardless of the shape of the triangle. This finding is somewhat similar to previous data for path integration with vision only (Péruch et al 1997) showing that participants are not very sensitive to triangle shape over this range of values and produce more or less the same angle for the entire set while undershooting path length for the longer distances. This is in contrast to the performance with body senses only (Loomis et al 1993) where responses appear to be a compromise between correct performance and producing the same responses for all paths, indicating perhaps that the information from body senses is more accurate. As can be seen in figure 4, the responses in the current data appear to be similar to those one would expect if the triangle was always equilateral. However, this is not the entire story. Analyses of the variability of response yielded significant differences between triangles for the SD of absolute angle (Leg $2 \times$ Angle $A$ interaction: $F_{5,195}=202.6, p<0.01$ ). Variability in absolute angle tend to be lower for isosceles triangles than for their non-isosceles counterparts with matched interior angles. However, when angle $A$ was $120^{\circ}$, this trend was reversed. These changes in variability across triangles are indicative of some sensitivity to triangle shape. However, the overall similarity of responses suggests that the differences in triangle shape were not large enough to yield discriminant behavior. Triangles were varied more in experiment 2 . 
In addition, there is an interaction of arena and triangle shape for angular error (Arena $\times \operatorname{Leg} 2 \times$ Angle $A: F_{17,592}=8.58, \quad p<0.01$ ) and the SD of absolute angle $\left(F_{17,195}=26.6, p<0.01\right)$. These interactions are the result of three exceptions to the separate arena and triangle effects already described. First, turn responses for triangle e (see table 1 for dimensions) resulted in a greater difference in angular error between arena $\mathrm{F}$ and the other two arenas ( $\mathrm{B}$ and $\mathrm{W}$ ) than for any other triangle. Second, the data exhibit two exceptions to the general trend for variability in absolute error. Variability for triangle a was lower for arena $F$ as compared to the other two arenas. Also, triangle $\mathrm{b}$ exhibited lower variability for arena $\mathrm{W}$ as compared to the other two display conditions. These 'exceptions' to the arena and triangle effects, however, do not provide additional insights into the trends previously described.

Another related interaction is an Arena $\times$ Angle $A \times$ Trial effect for position error $\left(F_{8,72}=2.26, p<0.05\right)$, and angular error $\left(F_{26,592}=4.46, p<0.01\right)$. Responses changed more across trials with arena $\mathrm{W}$ than with either arena $\mathrm{B}$ or $\mathrm{F}$, and this variability depended on triangle shape. For the two triangles that had an angle $A$ equal to $60^{\circ}$, error in arena $\mathrm{W}$ decreased across trials. In contrast, error increased across trials for the other four triangles. For arenas B and F, responses did not differ across trials.

Finally, we observed three gender effects. Women tended to turn about $10^{\circ}$ farther than men (angular error, $F_{1,592}=9.45, p<0.01$; absolute angle, $F_{1,592}=8.83, p<0.01$ ) but this difference was not consistent for the different triangle shapes. Women also exhibited significantly greater variability in response than did men (SD of path length error, $F_{1,9}=5.95, p<0.01$; SD of angular error, $F_{1,195}=25.84, p<0.01$; SD of absolute angle, $\left.F_{1,195}=24.61, p<0.01\right)$. Men and women exhibited different trends across the three trials (Gender $\times$ Trial interaction) for the length measures (path length error, $F_{2,18}=6.1, p<0.01$; path length, $F_{2,18}=6.24, p<0.01$ ): women tended to be more accurate on their first trial than men, but became increasingly less accurate, whereas men showed improved performance across trials. These effects indicate possible gender differences in strategy and performance certainty. Gender-related strategy differences will become more apparent in experiment 2.

The stereotyped response across triangles observed in this experiment could reflect the use of a strategy other than path integration. In particular, a timing strategy might be used in which distances are estimated from the number of seconds the joystick is pushed forward, and turns are estimated from the number of seconds the joystick is pushed sideways. These time-based distance and angle estimates could then be combined to determine the return path. If a timing strategy is employed, or if distances are estimated from the marker poles, then performance should be comparable in an environment without any texture, lacking optic flow information. However, if participants depend on optic flow for path integration, then we should see a dramatic decline in performance. Alternatively, responses might be stereotyped because the texture in the arenas failed to provide sufficient salient optic flow. A cluttered arena with objects at eye height could provide more salient motion parallax information for translation and flow for rotation, allowing improved accuracy. Such an environment was also tested in experiment 2.

\section{Experiment 2: Optic flow, motion parallax, and no flow}

Experiment 1 showed that people respond differently depending on the amount of texture in the environment, suggesting that they can use optic flow to perform path integration in a homing task. However, experiment 1 also raised questions about the discriminability of different triangle shapes, alternative strategies to integration of optic flow, and the possibility of improved performance with the availability of motion parallax. These issues were addressed in experiment 2. First, we tested a wider range of triangle shapes. Second, we replicated arena B and tested two new arena displays 
in addition to arena B. An arena with neither floor nor wall texture (arena N) was presented to address the question of whether participants judged distance from target poles or used a timing strategy rather than an optic flow integration strategy. An arena containing a 'forest' of vertical posts (arena P) was presented to test if the added motion parallax could improve path length accuracy.

\subsection{Methods}

4.1.1 Displays and triangles. Three arena conditions were tested to address questions raised in the first experiment (see figure 5). To allow us to make comparisons across experiments, arena $\mathrm{B}$ was repeated as a control. Arena $\mathrm{N}$ contained a white floor and a blue wall with no texture in the environment so that motion was defined minimally by the expanding target poles alone. Arena $\mathrm{P}$ contained an array of 200 vertical posts randomly positioned within the arena space and textured with the same pattern as that used for floor and wall texture in arena B. Posts were $25 \mathrm{~cm}$ in radius and $330 \mathrm{~cm}$ high (about twice eye height). The floor and walls were the same solid colors as those

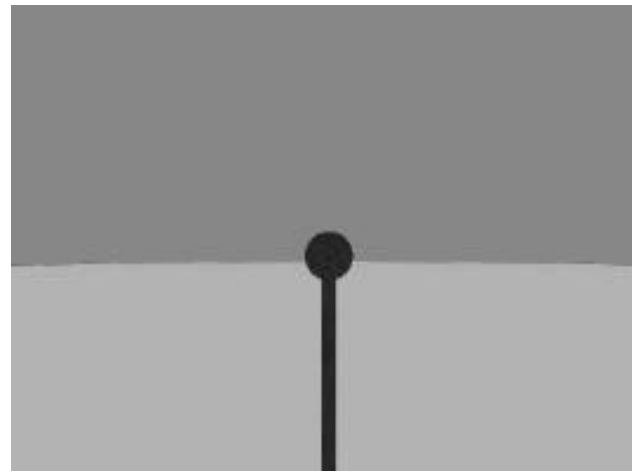

(a)

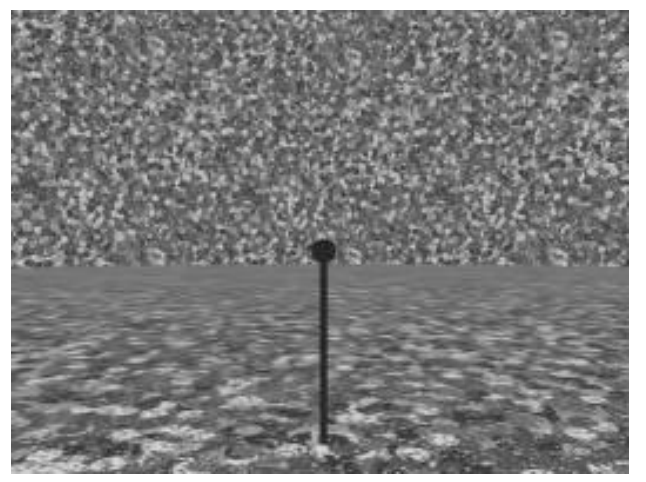

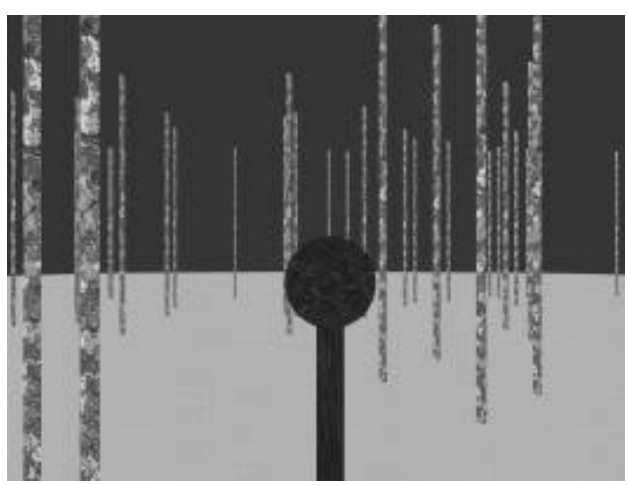

(b)

Figure 5. Arenas used for experiment 2. (a) Arena $\mathrm{N}$ with neither floor nor wall texture, (b) arena $\mathrm{P}$ with local textured poles, and (c) arena $\mathrm{B}$ with both floor wall and texture.

(c)

Table 3. Experiment 2. Triangle stimuli dimensions. Angle $A$ is the interior angle between Leg 1 and Leg 2 (see figure 1 for clarity).

\begin{tabular}{llll}
\hline Triangle & Leg $1 / \mathrm{cm}$ & Leg $2 / \mathrm{cm}$ & Angle $A /^{\circ}$ \\
\hline $\mathrm{a}$ & 425 & 225 & 60 \\
$\mathrm{~b}$ & 425 & 225 & 90 \\
$\mathrm{c}$ & 425 & 225 & 120 \\
$\mathrm{~g}$ & 225 & 225 & 60 \\
$\mathrm{~h}$ & 375 & 375 & 90 \\
$\mathrm{i}$ & 525 & 525 & 120 \\
\hline
\end{tabular}


in arena $\mathrm{N}$. The arrangement of the posts was randomly changed on every trial. As described in table 3 (see also figure 6), a different set of triangles was used. Three were the same as in experiment 1 and three had a larger range of leg lengths, including variation in the total outbound path length.

4.1.2 Participants. Eleven naïve participants, six men and five women, were included in the experimental analyses. One additional male participant was excluded from the analyses because he was an extreme outlier (turn responses that were $180^{\circ}$ different from the norm and path length estimates that were much shorter in all arenas). An additional six women and one man dropped out owing to simulator sickness.

\subsection{Results and discussion}

Mixed design ANOVAs (Arena $\times$ Triangle $\times$ Trial $\times$ Gender) were run for the path length measures. For each independent variable, the angular measures were analyzed with one-way Watson-Williams tests. The ANOVAs revealed significant effects of arena, triangle shape, and gender for responses and response variability. There were no trial effects. In contrast to experiment 1 , however, men and women exhibited very different patterns of behavior with respect to the arena and triangle shape.

As seen in figure 6 and tables 4 and 5, the gender response differences are quite dramatic (Gender $\times$ Arena interaction: path length error, $F_{2,18}=7.65, p<0.01$; path length, $F_{2,18}=7.42, p<0.01$; angular error, $F_{5,592}=23.82, p<0.01$; absolute angle, $\left.F_{5,592}=33.13, p<0.01\right)$ although there were no significant differences in variability of response. Separate analyses for men and women on the same response measures yielded significant effects of arena in both cases. However, women's responses were of a smaller magnitude and were the result of different data patterns. Men exhibited dramatic performance differences for different arenas (path length error, $F_{2,10}=14.26$, $p<0.01$; path length, $F_{2,10}=13.85, p<0.01$; angular error, $F_{2,322}=7.49, p<0.01$; absolute angle, $F_{2,322}=8.86, p<0.01$ ). Men were most accurate with arena $\mathrm{B}$, which had the most optic flow information for integrating translational and rotational motion. Their performance was also accurate for path length in arena $\mathrm{P}$, consistent with the use of motion parallax to estimate distances traveled, although the turn angle was underestimated relative to angular responses in arena B. In contrast, men essentially responded at random in the arena $\mathrm{N}$ display condition, where self-motion could not be determined very accurately from optic flow (since there was very minimal visual flow information). As discussed in experiment 1 , this result indicates that there was not enough information about self-motion available from the target poles on the outbound path (time to contact, change of the angle of elevation in the visual scene) for estimation of distances traveled.

Women also showed a significant effect of arena (figure 6a) (path length error, $F_{2,8}=6.12, p<0.05$; path length, $F_{2,8}=6.00, p<0.05$; angular error, $F_{2,268}=6.00$, $p<0.01$; absolute angle, $F_{2,268}=7.9, p<0.01$ ). Both men and women showed an increase in the variability of turn responses in the condition with minimal optic flow ( $\operatorname{arena} \mathrm{N}$ ), although the trend is more pronounced for men than women (arena, response variability: angular error, $F_{32,196}=20.46, p<0.01$; absolute angle, $F_{32,196}=20.00$, $p<0.01$ ). However, the pattern of responses was quite different (Arena $\times$ Gender, response: path length error, $F_{2,18}=7.65, p<0.01$; path length, $F_{2,18}=7.42, p<0.01$ ). For women, path lengths were most accurate for arena B, and increasingly underestimated for arenas $\mathrm{N}$ and $\mathrm{P}$, respectively. In contrast to the pattern exhibited by men, this does not fall in line with the hypothesis of path integration from optic flow. In fact, path length estimates by women for arena $\mathrm{N}$ were more accurate than responses by men in the same no texture environment by a factor of two $(-104 \mathrm{~cm}$ versus $-210 \mathrm{~cm}$ ), suggesting they relied on a different strategy not based on optic flow. Women's average turn responses reflect a tendency to underturn for arena B and 

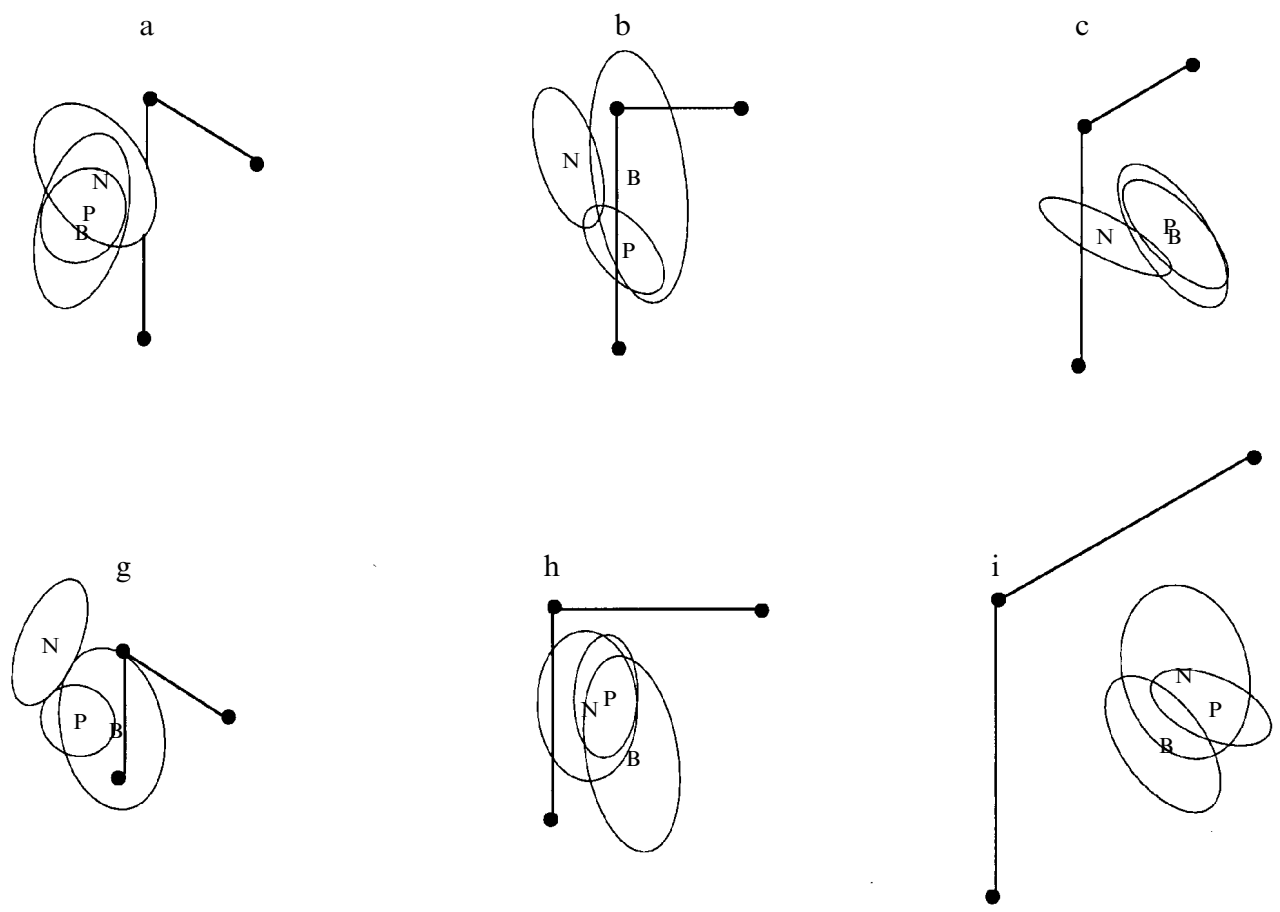

(a)
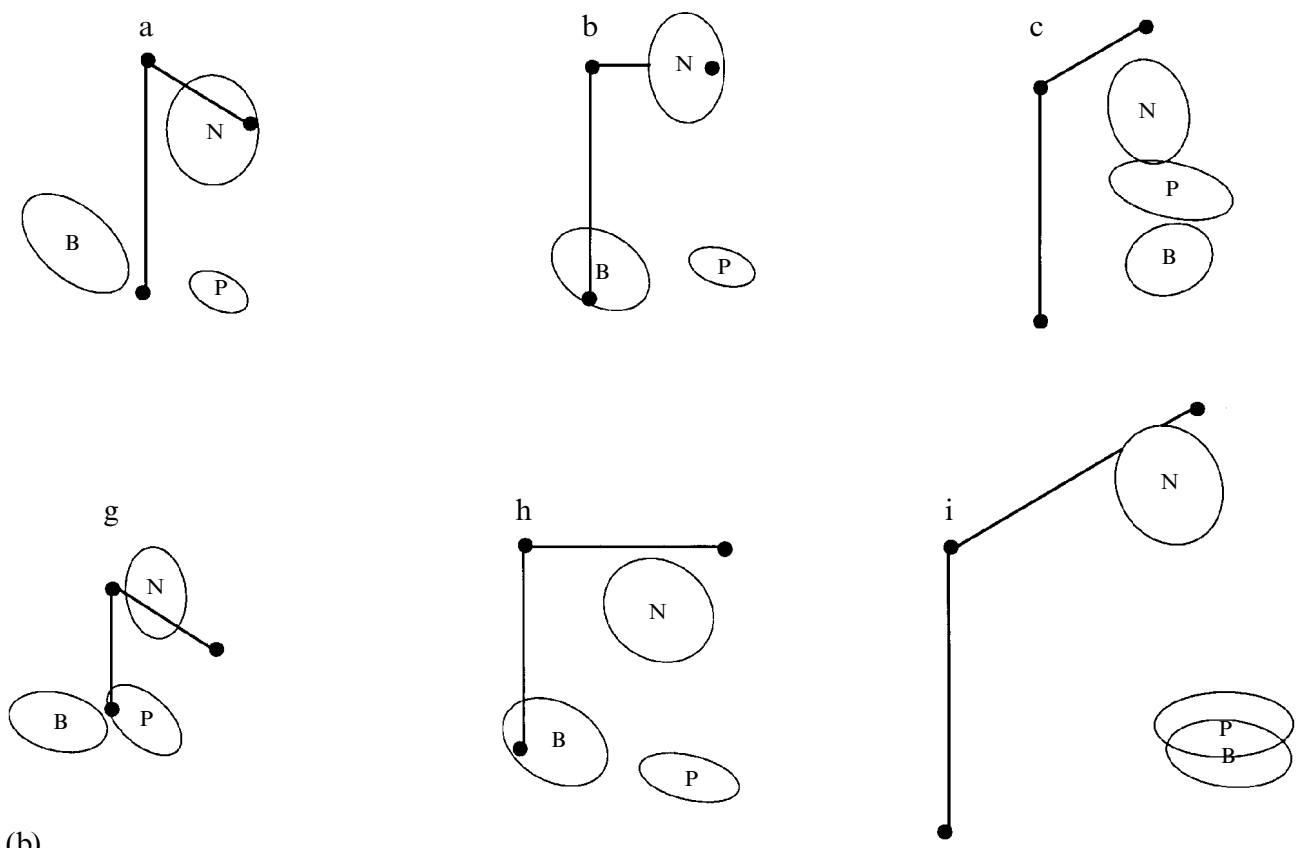

(b)

Figure 6. $95 \%$ confidence ellipses of responses for each arena for all triangles for experiment 2 . Label in the center of the ellipse indicates the arena display condition and also marks the location of the population mean. (a) Data from female participants, (b) data from male participants. Note the significant differences in responses between the arenas in the men's data set and the lack of systematic differences across arenas for the women's data. 
Table 4. Experiment 2. Means and standard deviations (in parentheses) for women for all conditions.

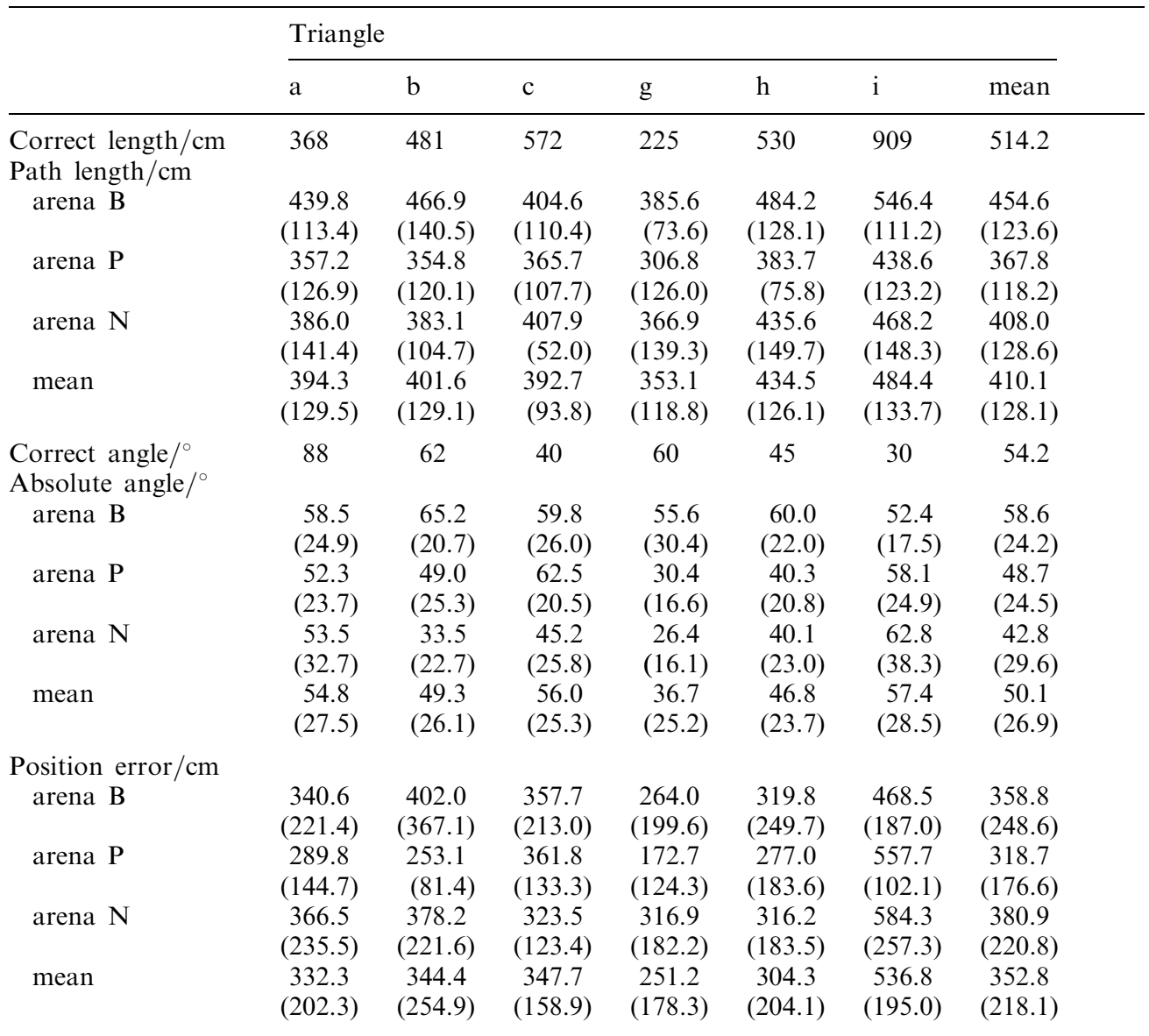

overturn for arena N. Women's turn responses were also more accurate than men's for all arenas. Since women did exhibit a small but significant decline in accuracy when optic flow information was minimal or absent, it suggested that women relied partially on optic flow to estimate self-motion, but may have also used information from marker poles or a timing strategy, resulting in more stereotyped responses than those observed in the men's data.

These patterns of responses indicate that men are more sensitive to, and dependent on, optic flow information for path integration than our women participants. It was evident in experiment 1 that gender played a role in strategy use and response variability, but the Arena $\times$ Gender effect observed in the current experiment make these gender differences in strategy use more apparent. However, as we will describe below, these data must be interpreted with caution.

Unlike the previous experiment, participants responded differentially to the different triangles (path length, $F_{5,45}=26.45, p<0.01$; absolute angle, $F_{5,592}=5.48, p<0.01$; position error, $F_{5,45}=46.05, p<0.01$; response variability: path length error, $F_{5,45}=2.43, p<0.05$ ). However, these data still tended toward stereotyped responses biased toward an equilateral triangle, even though the triangle set presented in experiment 2 was more diverse. In addition, triangle shape affected performance differently for men and women (Triangle $\times$ Gender: absolute angle, $F_{11,592}=14.61, p<0.01$; position error, $F_{5,45}=2.75, p<0.05$; Triangle $\times$ Gender, response variability: path length, 
Table 5. Experiment 2. Means and standard deviations (in parentheses) for men for all conditions.

\begin{tabular}{|c|c|c|c|c|c|c|c|}
\hline & \multicolumn{7}{|c|}{ Triangle } \\
\hline & $\mathrm{a}$ & $\mathrm{b}$ & $\mathrm{c}$ & g & $\mathrm{h}$ & $\mathrm{i}$ & mean \\
\hline \multirow{3}{*}{$\begin{array}{l}\text { Correct length } / \mathrm{cm} \\
\text { Path length } / \mathrm{cm} \\
\text { arena B }\end{array}$} & 368 & 481 & 572 & 225 & 530 & 909 & 514.2 \\
\hline & & & & & & & \\
\hline & $\begin{array}{c}484.8 \\
(120.3)\end{array}$ & $\begin{array}{c}481.9 \\
(134.9)\end{array}$ & $\begin{array}{c}464.7 \\
(149.6)\end{array}$ & $\begin{array}{c}429.9 \\
(136.7)\end{array}$ & $\begin{array}{c}538.9 \\
(189.9)\end{array}$ & $\begin{array}{c}645.3 \\
(113.5)\end{array}$ & $\begin{array}{c}507.6 \\
(156.1)\end{array}$ \\
\hline arena $\mathrm{P}$ & $\begin{array}{l}351.5 \\
(78.7)\end{array}$ & $\begin{array}{l}394.7 \\
(89.8)\end{array}$ & $\begin{array}{c}408.0 \\
(120.8)\end{array}$ & $\begin{array}{c}329.4 \\
(116.4)\end{array}$ & $\begin{array}{l}502.3 \\
(97.7)\end{array}$ & $\begin{array}{c}598.4 \\
(172.7)\end{array}$ & $\begin{array}{c}430.7 \\
(147.2)\end{array}$ \\
\hline arena $\mathrm{N}$ & $\begin{array}{l}307.1 \\
(80.7)\end{array}$ & $\begin{array}{l}283.2 \\
(67.0)\end{array}$ & $\begin{array}{c}301.9 \\
(118.6)\end{array}$ & $\begin{array}{l}244.7 \\
(84.4)\end{array}$ & $\begin{array}{c}341.2 \\
(149.4)\end{array}$ & $\begin{array}{c}337.5 \\
(125.1)\end{array}$ & $\begin{array}{c}302.6 \\
(110.6)\end{array}$ \\
\hline mean & $\begin{array}{c}381.2 \\
(120.5)\end{array}$ & $\begin{array}{c}386.6 \\
(128.9)\end{array}$ & $\begin{array}{l}391.5 \\
(144.9)\end{array}$ & $\begin{array}{c}334.7 \\
(135.9)\end{array}$ & $\begin{array}{l}460.8 \\
(171.2)\end{array}$ & $\begin{array}{l}527.1 \\
(193.4)\end{array}$ & $\begin{array}{c}413.6 \\
(162.7)\end{array}$ \\
\hline Correct angle $/{ }^{\circ}$ & 88 & 62 & 40 & 60 & 45 & 30 & 54.2 \\
\hline \multicolumn{8}{|l|}{ Absolute angle $/{ }^{\circ}$} \\
\hline arena $\mathrm{B}$ & $\begin{array}{c}74.0 \\
(38.7)\end{array}$ & $\begin{array}{l}65.4 \\
(31.7)\end{array}$ & $\begin{array}{l}68.5 \\
(25.9)\end{array}$ & $\begin{array}{l}48.8 \\
(31.3)\end{array}$ & $\begin{array}{c}52.3 \\
(24.2)\end{array}$ & $\begin{array}{l}74.3 \\
(26.0)\end{array}$ & $\begin{array}{l}63.8 \\
(31.4)\end{array}$ \\
\hline arena $\mathrm{P}$ & $\begin{array}{l}111.9 \\
(23.4)\end{array}$ & $\begin{array}{l}95.2 \\
(20.7)\end{array}$ & $\begin{array}{l}71.0 \\
(35.4)\end{array}$ & $\begin{array}{l}68.7 \\
(26.6)\end{array}$ & $\begin{array}{l}79.8 \\
(26.5)\end{array}$ & $\begin{array}{l}75.5 \\
(25.6)\end{array}$ & $\begin{array}{c}83.9 \\
(30.4)\end{array}$ \\
\hline arena $\mathrm{N}$ & $\begin{array}{l}79.3 \\
(44.4)\end{array}$ & $\begin{array}{l}87.3 \\
(39.6)\end{array}$ & $\begin{array}{l}76.4 \\
(44.0)\end{array}$ & $\begin{array}{l}67.5 \\
(34.7)\end{array}$ & $\begin{array}{l}72.3 \\
(43.3)\end{array}$ & $\begin{array}{c}83.5 \\
(44.3)\end{array}$ & $\begin{array}{c}77.6 \\
(42.3)\end{array}$ \\
\hline mean & $\begin{array}{c}90.0 \\
(39.7)\end{array}$ & $\begin{array}{c}82.9 \\
(33.8)\end{array}$ & $\begin{array}{l}71.6 \\
(36.0)\end{array}$ & $\begin{array}{l}61.7 \\
(32.2)\end{array}$ & $\begin{array}{l}67.8 \\
(34.3)\end{array}$ & $\begin{array}{l}77.3 \\
(33.3)\end{array}$ & $\begin{array}{l}75.0 \\
(35.9)\end{array}$ \\
\hline \multirow{2}{*}{$\begin{array}{l}\text { Position error/cm } \\
\text { arena B }\end{array}$} & & & & & & & \\
\hline & $\begin{array}{c}301.5 \\
(187.5)\end{array}$ & $\begin{array}{c}258.3 \\
(120.3)\end{array}$ & $\begin{array}{c}342.2 \\
(111.9)\end{array}$ & $\begin{array}{c}251.9 \\
(108.7)\end{array}$ & $\begin{array}{c}274.4 \\
(138.3)\end{array}$ & $\begin{array}{c}590.0 \\
(225.1)\end{array}$ & $\begin{array}{c}336.4 \\
(191.7)\end{array}$ \\
\hline arena $\mathrm{P}$ & $\begin{array}{c}187.5 \\
(100.0)\end{array}$ & $\begin{array}{c}282.6 \\
(119.2)\end{array}$ & $\begin{array}{c}414.1 \\
(186.3)\end{array}$ & $\begin{array}{c}190.7 \\
(138.0)\end{array}$ & $\begin{array}{c}353.2 \\
(196.0)\end{array}$ & $\begin{array}{c}602.9 \\
(244.6)\end{array}$ & $\begin{array}{c}338.5 \\
(220.9)\end{array}$ \\
\hline arena $\mathrm{N}$ & $\begin{array}{c}393.7 \\
(219.2)\end{array}$ & $\begin{array}{c}500.1 \\
(218.0)\end{array}$ & $\begin{array}{c}484.9 \\
(181.9)\end{array}$ & $\begin{array}{c}286.5 \\
(170.5)\end{array}$ & $\begin{array}{c}449.5 \\
(196.7)\end{array}$ & $\begin{array}{c}807.1 \\
(230.0)\end{array}$ & $\begin{array}{c}487.0 \\
(255.6)\end{array}$ \\
\hline mean & $\begin{array}{c}294.2 \\
(192.7)\end{array}$ & $\begin{array}{c}347.0 \\
(191.0)\end{array}$ & $\begin{array}{c}413.7 \\
(170.9)\end{array}$ & $\begin{array}{c}243.0 \\
(144.3)\end{array}$ & $\begin{array}{c}359.0 \\
(190.0)\end{array}$ & $\begin{array}{c}666.7 \\
(249.9)\end{array}$ & $\begin{array}{c}387.3 \\
(234.4)\end{array}$ \\
\hline
\end{tabular}

$\left.F_{5,45}=3.18, p<0.05\right)$. Accuracy for both men and women improved from large to small triangles, but women were more accurate than men for the largest triangle. These results indicate that triangle shape influences performance when the set of triangles is sufficiently varied.

On the basis of these data, it seems clear that optic flow can be used for path integration in a homing task. The current experiment reinforces two observations from experiment 1: first, that the available optic flow does differentially influence homing performance; and, second, that men and women may use the visual information about self-motion differently.

However, the strong gender effects found in experiment 2 need to be interpreted with caution. The overwhelming impression from the current data is that women perform with little regard to the optic flow, indicating reliance on information from marker poles or a timing strategy. Alternatively, men appear to rely on the optic flow information for path integration. However, this needs to be interpreted in light of the attrition rate. In the current experiment, more than half the women who entered the study experienced simulator sickness and were unable to complete the experiment; in contrast, only one male participant dropped out. (Unequal attrition was also observed in experiment 1, but without any performance differences related to the visual environment.) Previous reports (Hye Young Park and Hu 1999; Jokerst et al 1999; Yoo 2000) have indicated that women tend to be more susceptible to motion and simulator sickness. Symptoms 
of simulator sickness are often associated with sensory 'conflict', such as inconsistency between a visual display specifying self-motion and efferent, vestibular, or proprioceptive information specifying no motion. It is thus possible that women who were able to complete the experiment were those who tended to disregard (consciously or unconsciously) the optic flow information about self-motion, thereby minimizing sensory conflict. This could explain the reduced arena effect among women and their reliance on another strategy, such as timing. Therefore, the gender differences found in experiment 2 could be (in part) a consequence of the visual-vestibular conflict in the laboratory rather than a more general gender difference in visual strategies for homing.

Manipulating the visual information about self-motion during active walking would allow us to examine the role of optic flow when information from the body senses is simultaneously available, as it is in normal locomotion. In addition, this would reduce the sensory conflict that may have produced unequal attrition and an artificial gender difference in the present experiment. Therefore, in experiment 3 we examined the role of visual information for homing during active walking.

\section{Experiment 3: Active walking with and without optic flow}

The two joystick experiments with vision alone indicate that people can perform path integration from optic flow. However, during normal walking other information about self-motion is also available from body senses, including proprioceptive, vestibular, and movement-specific efferent information, as well as from visual landmarks. In experiment 3, we tested the contributions of both optic flow and the body senses for path integration by comparing arena $\mathrm{B}$, with both flow and information from body senses, arena $\mathrm{F}$ with reduced rotational flow, and arena $\mathrm{N}$, with minimal optic flow and information primarily from body senses. If the combination of optic flow and body senses provides an advantage, performance should be best in arena B. Arena F allows us to assess whether optic flow contributes to estimating the rotation angle, or whether the body senses are sufficient, as suggested by previous research (Bakker et al 1999; Rieser 1989; Rieser et al 1986). Finally, arena N permits us to determine whether optic flow contributes to path integration during locomotion, or whether people normally rely on the body senses. It is nearly analogous to the blind-walking task of Loomis et al (1993), except that our task allows participants to actively walk along the path to seen target poles, which (as mentioned before) offer minimal flow information as they are approached.

\subsection{Methods}

In experiment 3, participants wore the HMD while actively walking in the virtual environments. If a participant reached the perimeter of the tracking area on the response leg, an alarm would sound, signaling that the person should stop immediately and the position at which he or she left the tracking area was recorded.

5.1.1 Displays and triangles. Three of the previous arenas were tested. Arena B presented texture on both the floor and walls, arena $\mathrm{F}$ had texture on the floor only, and arena $\mathrm{N}$ contained neither wall nor floor texture. The three triangles used in both experiments 1 and 2 were tested again, as well as three new triangles that had the reverse leg 1 and leg 2 lengths (see table 6). This provided a qualitatively diverse triangle set that incorporated triangles with two different leg 1 lengths to check for a tendency to replicate the first leg length, and eliminated 'special' triangles, such as isosceles and equilateral triangles. This way, none of the triangles has predictable or easily represented responses due to any regular properties of 'special' triangles.

5.1.2 Participants. Data from twelve naïve participants (six men and six women) were included in the experimental analyses. It is important to note that all participants 
Table 6. Experiment 3. Triangle stimuli dimensions. Angle $A$ is the interior angle between Leg 1 and Leg 2 (see figure 1 for clarity).

\begin{tabular}{llll}
\hline Triangle & Leg $1 / \mathrm{cm}$ & Leg $2 / \mathrm{cm}$ & Angle $A /^{\circ}$ \\
\hline $\mathrm{a}$ & 425 & 225 & 60 \\
$\mathrm{~b}$ & 425 & 225 & 90 \\
$\mathrm{c}$ & 425 & 225 & 120 \\
$\mathrm{j}$ & 225 & 425 & 60 \\
$\mathrm{k}$ & 225 & 425 & 90 \\
$\mathrm{l}$ & 225 & 425 & 120 \\
\hline
\end{tabular}

were able to complete the experiment without simulator sickness. This supports findings in Chance et al (1998) that the more physical control a person has in a virtual environment, the less likely he or she is to experience uncomfortable symptoms. Truncated trials (trials that went outside the tracking volume) accounted for only $2 \%$ of all trials and at most $7 \%$ of any given participant's trials (four trials). Half the participants had no truncated trials. In addition, there was no gender bias in the pattern of truncation, and no specific triangle or arena was more likely to result in a truncated trial than any other. Although these data points created a ceiling effect that skewed the data away from overshooting, dropping the truncated trials would have only increased such a skew. Therefore, all truncated trials were included in the analyses.

\subsection{Results and discussion}

The pattern of responses during active walking was strikingly different from that in experiments 1 and 2 (figure 7 and table 7). First, responses were much more consistent, resulting in small error ellipses. Second, there was systematic overshooting (rather than undershooting) in turn angle and path length. Third, for the first time there were no significant differences between arenas. Performance was nearly identical with and without optic flow, as long as information from body senses was available. Mixed-design ANOVAs (Arena $\times$ Leg $1 \times$ Angle $A \times$ Trial $\times$ Gender) were run on the linear measures, whereas the angular measures were analyzed with one-way Watson - Williams tests.
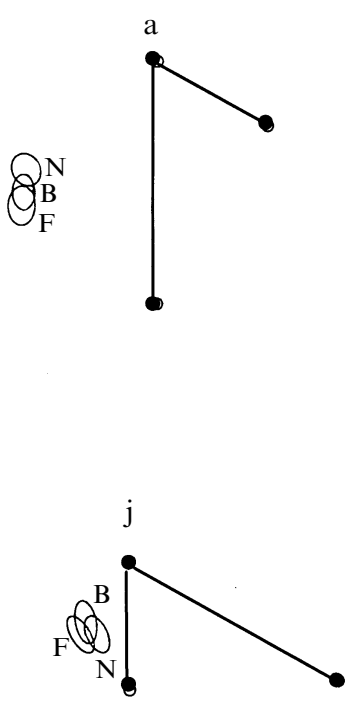

Figure 7. 95\% confidence ellipses of responses for each arena for all triangles for experiment 3. Label to the side of the ellipse indicates the arena display condition. Ellipse centroid marks the location of the population mean. 
Table 7. Experiment 3. Means and standard deviations (in parentheses) for all conditions.

\begin{tabular}{|c|c|c|c|c|c|c|c|}
\hline & \multicolumn{7}{|c|}{ Triangle } \\
\hline & $\mathrm{a}$ & $\mathrm{b}$ & $\mathrm{c}$ & $\mathrm{j}$ & $\mathrm{k}$ & 1 & mean \\
\hline \multirow{3}{*}{$\begin{array}{l}\text { Correct length } / \mathrm{cm} \\
\text { Path length } / \mathrm{cm} \\
\text { arena B }\end{array}$} & 368 & 481 & 572 & 368 & 481 & 572 & 473.7 \\
\hline & & & & & & & \\
\hline & $\begin{array}{c}461.6 \\
(108.3)\end{array}$ & $\begin{array}{c}500.0 \\
(101.2)\end{array}$ & $\begin{array}{c}487.8 \\
(119.8)\end{array}$ & $\begin{array}{c}472.6 \\
(103.0)\end{array}$ & $\begin{array}{l}504.2 \\
(99.2)\end{array}$ & $\begin{array}{c}478.1 \\
(111.0)\end{array}$ & $\begin{array}{c}484.0 \\
(107.1)\end{array}$ \\
\hline arena $\mathrm{F}$ & $\begin{array}{c}481.9 \\
(114.8)\end{array}$ & $\begin{array}{c}494.6 \\
(115.4)\end{array}$ & $\begin{array}{c}499.0 \\
(89.3)\end{array}$ & $\begin{array}{c}477.0 \\
(99.3)\end{array}$ & $\begin{array}{l}478.0 \\
(71.8)\end{array}$ & $\begin{array}{c}486.3 \\
(81.7)\end{array}$ & $\begin{array}{c}486.1 \\
(96.0)\end{array}$ \\
\hline arena $\mathrm{N}$ & $\begin{array}{c}446.4 \\
(128.6)\end{array}$ & $\begin{array}{c}482.8 \\
(106.2)\end{array}$ & $\begin{array}{c}464.8 \\
(105.2)\end{array}$ & $\begin{array}{c}444.7 \\
(111.3)\end{array}$ & $\begin{array}{l}465.7 \\
(99.5)\end{array}$ & $\begin{array}{l}498.3 \\
(87.8)\end{array}$ & $\begin{array}{c}467.1 \\
(107.6)\end{array}$ \\
\hline men & $\begin{array}{c}474.9 \\
(137.0)\end{array}$ & $\begin{array}{c}503.5 \\
(126.3)\end{array}$ & $\begin{array}{c}479.1 \\
(112.9)\end{array}$ & $\begin{array}{c}485.9 \\
(118.4)\end{array}$ & $\begin{array}{c}492.0 \\
(106.4)\end{array}$ & $\begin{array}{c}491.2 \\
(107.6)\end{array}$ & $\begin{array}{c}487.8 \\
(118.0)\end{array}$ \\
\hline women & $\begin{array}{c}451.7 \\
(93.6)\end{array}$ & $\begin{array}{c}481.4 \\
(83.1)\end{array}$ & $\begin{array}{c}488.6 \\
(98.4)\end{array}$ & $\begin{array}{c}443.6 \\
(84.8)\end{array}$ & $\begin{array}{c}473.2 \\
(74.1)\end{array}$ & $\begin{array}{c}483.9 \\
(78.5)\end{array}$ & $\begin{array}{c}470.4 \\
(86.8)\end{array}$ \\
\hline mean & $\begin{array}{c}463.3 \\
(117.4)\end{array}$ & $\begin{array}{c}492.5 \\
(107.0)\end{array}$ & $\begin{array}{c}483.9 \\
(105.5)\end{array}$ & $\begin{array}{c}464.8 \\
(104.7)\end{array}$ & $\begin{array}{l}482.6 \\
(91.7)\end{array}$ & $\begin{array}{l}487.6 \\
(93.8)\end{array}$ & $\begin{array}{c}479.1 \\
(103.9)\end{array}$ \\
\hline \multicolumn{8}{|l|}{$\begin{array}{l}\text { Correct angle } /{ }^{\circ} \\
\text { Absolute angle } /^{\circ}\end{array}$} \\
\hline arena $\mathrm{B}$ & $\begin{array}{c}45.2 \\
(20.7)\end{array}$ & $\begin{array}{c}45.7 \\
(21.1)\end{array}$ & $\begin{array}{c}42.7 \\
(17.1)\end{array}$ & $\begin{array}{c}22.1 \\
(20.3)\end{array}$ & $\begin{array}{c}23.3 \\
(17.4)\end{array}$ & $\begin{array}{c}23.5 \\
(14.7)\end{array}$ & $\begin{array}{c}33.7 \\
(21.5)\end{array}$ \\
\hline arena $\mathrm{F}$ & $\begin{array}{c}50.0 \\
(20.1)\end{array}$ & $\begin{array}{c}43.7 \\
(20.6)\end{array}$ & $\begin{array}{c}39.0 \\
(20.1)\end{array}$ & $\begin{array}{c}24.2 \\
(22.0)\end{array}$ & $\begin{array}{c}28.4 \\
(20.6)\end{array}$ & $\begin{array}{c}23.6 \\
(16.1)\end{array}$ & $\begin{array}{c}34.8 \\
(22.3)\end{array}$ \\
\hline arena $\mathrm{N}$ & $\begin{array}{c}42.2 \\
(20.5)\end{array}$ & $\begin{array}{c}40.3 \\
(15.4)\end{array}$ & $\begin{array}{c}28.6 \\
(19.7)\end{array}$ & $\begin{array}{c}26.4 \\
(18.1)\end{array}$ & $\begin{array}{c}20.5 \\
(14.8)\end{array}$ & $\begin{array}{c}20.7 \\
(15.0)\end{array}$ & $\begin{array}{c}29.7 \\
(19.3)\end{array}$ \\
\hline men & $\begin{array}{r}43.4 \\
(18.4)\end{array}$ & $\begin{array}{c}38.9 \\
(19.3)\end{array}$ & $\begin{array}{c}36.7 \\
(20.8)\end{array}$ & $\begin{array}{l}23.7 \\
(20.5)\end{array}$ & $\begin{array}{c}25.2 \\
(18.8)\end{array}$ & $\begin{array}{c}22.1 \\
(14.9)\end{array}$ & $\begin{array}{c}31.7 \\
(20.5)\end{array}$ \\
\hline women & $\begin{array}{c}48.3 \\
(22.5)\end{array}$ & $\begin{array}{c}47.5 \\
(18.5)\end{array}$ & $\begin{array}{c}36.9 \\
(19.0)\end{array}$ & $\begin{array}{c}24.8 \\
(20.1)\end{array}$ & $\begin{array}{c}22.9 \\
(17.1)\end{array}$ & $\begin{array}{c}23.0 \\
(15.7)\end{array}$ & $\begin{array}{c}33.8 \\
(21.7)\end{array}$ \\
\hline mean & $\begin{array}{c}45.8 \\
(20.7)\end{array}$ & $\begin{array}{c}43.2 \\
(19.3)\end{array}$ & $\begin{array}{c}36.8 \\
(19.9)\end{array}$ & $\begin{array}{c}24.3 \\
(20.3)\end{array}$ & $\begin{array}{c}24.0 \\
(18.0)\end{array}$ & $\begin{array}{c}22.6 \\
(15.3)\end{array}$ & $\begin{array}{c}32.7 \\
(21.1)\end{array}$ \\
\hline \multicolumn{8}{|l|}{ Position error/cm } \\
\hline arena $\mathrm{B}$ & $\begin{array}{c}340.1 \\
(128.3)\end{array}$ & $\begin{array}{c}215.3 \\
(117.4)\end{array}$ & $\begin{array}{c}208.6 \\
(112.8)\end{array}$ & $\begin{array}{c}236.3 \\
(122.2)\end{array}$ & $\begin{array}{c}207.4 \\
(131.9)\end{array}$ & $\begin{array}{c}246.4 \\
(132.4)\end{array}$ & $\begin{array}{c}242.4 \\
(131.3)\end{array}$ \\
\hline arena $\mathrm{F}$ & $\begin{array}{c}336.2 \\
(152.2)\end{array}$ & $\begin{array}{c}233.1 \\
(121.0)\end{array}$ & $\begin{array}{c}236.7 \\
(151.0)\end{array}$ & $\begin{array}{c}221.3 \\
(117.6)\end{array}$ & $\begin{array}{c}189.3 \\
(151.3)\end{array}$ & $\begin{array}{l}239.3 \\
(99.9)\end{array}$ & $\begin{array}{c}242.6 \\
(139.7)\end{array}$ \\
\hline arena $\mathrm{N}$ & $\begin{array}{c}354.9 \\
(156.6)\end{array}$ & $\begin{array}{c}222.2 \\
(130.7)\end{array}$ & $\begin{array}{c}241.9 \\
(121.4)\end{array}$ & $\begin{array}{c}195.9 \\
(132.0)\end{array}$ & $\begin{array}{c}207.8 \\
(123.5)\end{array}$ & $\begin{array}{c}238.0 \\
(105.8)\end{array}$ & $\begin{array}{c}243.4 \\
(138.1)\end{array}$ \\
\hline men & $\begin{array}{c}372.6 \\
(155.3)\end{array}$ & $\begin{array}{c}262.0 \\
(127.3)\end{array}$ & $\begin{array}{c}263.2 \\
(144.7)\end{array}$ & $\begin{array}{c}248.5 \\
(148.0)\end{array}$ & $\begin{array}{c}224.8 \\
(160.8)\end{array}$ & $\begin{array}{c}240.1 \\
(120.4)\end{array}$ & $\begin{array}{c}268.5 \\
(150.4)\end{array}$ \\
\hline women & $\begin{array}{c}314.8 \\
(129.1)\end{array}$ & $\begin{array}{c}185.1 \\
(104.6)\end{array}$ & $\begin{array}{c}194.9 \\
(101.6)\end{array}$ & $\begin{array}{l}187.2 \\
(85.2)\end{array}$ & $\begin{array}{l}178.2 \\
(99.4)\end{array}$ & $\begin{array}{c}242.3 \\
(105.3)\end{array}$ & $\begin{array}{c}217.1 \\
(115.0)\end{array}$ \\
\hline mean & $\begin{array}{c}343.7 \\
(145.1)\end{array}$ & $\begin{array}{c}223.5 \\
(122.2)\end{array}$ & $\begin{array}{c}229.1 \\
(129.1)\end{array}$ & $\begin{array}{c}217.8 \\
(124.0)\end{array}$ & $\begin{array}{c}201.5 \\
(135.1)\end{array}$ & $\begin{array}{c}241.2 \\
(112.6)\end{array}$ & $\begin{array}{c}242.8 \\
(136.2)\end{array}$ \\
\hline
\end{tabular}

The only significant effect relating to the display conditions was an Arena $\times$ Triangle interaction (path length error, $F_{10,100}=2.06, p<0.05$; path length, $F_{10,100}=$ 2.13, $p<0.05$; angular error, $F_{17,646}=10.94, p<0.01$; absolute angle, $F_{17,646}=31.30$, $p<0.01$ ). However, as seen in figure 7 and table 7 , this is the result of significantly different responses between arenas for one triangle (triangle k), and even here it is a very small difference. In this one case, arena $\mathrm{F}$ elicited less turning than arena $\mathrm{B}$, as in experiment 1 . Overall, these data exhibit a different response pattern from the previous experiments when only flow was available, characterized by overturning and overshooting the home location. The fact that there were no other arena effects or interactions indicates that responses were the same whether or not optic flow was present. Taken together 
this is a strong indication that participants relied predominantly on the body senses rather than visual information from optic flow to perform homing.

The current experiment did yield significant differences between trials and between triangles. Trial effects (path length error, $F_{2,20}=7.74, p<0.01$; path length, $F_{2,20}=$ 8.17, $p<0.01)$ in the current experiment reveal a positive learning trend. Participants tended to undershoot the final leg length in the first trial and become increasingly more accurate by the third trial for all conditions. In combination with the reduced variability of response, this supports the idea that motor information is useful in learning and estimating distances traveled.

Significant Leg $1 \times$ Angle $A$ interactions were also found for all measures (path length, $F_{5,50}=4.36, p<0.01$; absolute angle, $\left.F_{5,646}=32.78, p<0.01\right)$ indicating a degree of sensitivity to differences in triangle shape. However, there was still a bias toward stereotyped responses, indicated by the significant result for position error (position error, $\left.F_{5,50}=6.13, p<0.01\right)$ as we observed in the vision-only experiments. As can be seen in figure 7 , there remains a tendency to overshoot acute triangles and undershoot obtuse ones.

There was also an interaction between triangle shape and gender (Leg $1 \times$ Angle $A$ $\times$ Gender: angular error, $F_{11,646}=45.55, p<0.01$; absolute angle, $F_{11,646}=15.14$, $p<0.01$ ). As shown in figure 8 and table 7 , men tended to turn more for the smaller angles than women, although men and women turned about the same amount for the triangles where the angle $A$ was $120^{\circ}$. This tendency for men to turn farther than women contrasts with the gender effect in experiment 1 , where men consistently turned less than women did in their responses. In both cases, the result was more accurate angle estimations by women than men.
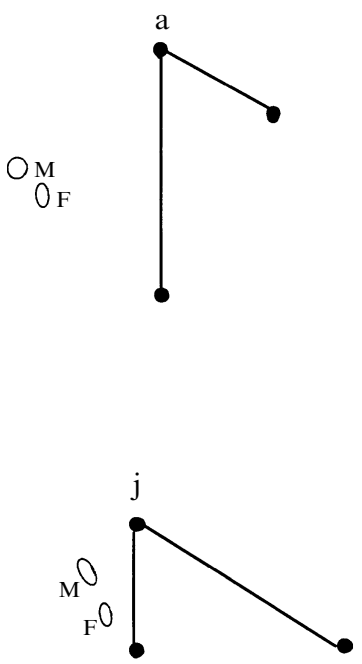
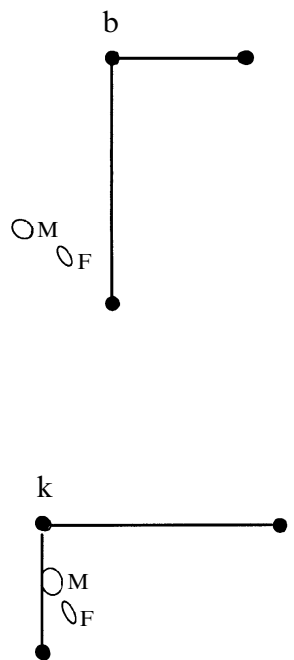
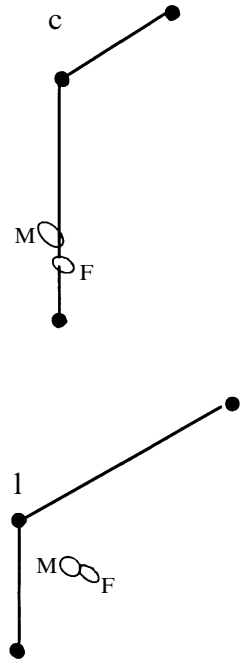

Figure 8. 95\% confidence ellipses of responses for each gender for all triangles for experiment 3 . Label at the side of the ellipse indicates the gender. Ellipse centroid marks the location of the population mean.

\section{Comparison of experiments 1 and 3}

In order to compare performance across the three experiments, experiments 2 and 3 contained a partial replication of Experiment 1 for three triangles in arena B (see top rows of figures $4,6,7$, and 8 ). However, given the different response pattern for men and women in experiment 2 (possibly due to the high attrition rate for women) it seemed prudent to compare experiments 1 and 3. The ANOVAs yielded a significant reduction in the variability of final-turn responses (SD of angular error, $F_{1,66}=11.03$, 
$p<0.01$; SD of absolute angle, $\left.F_{1,66}=10.58, p<0.01\right)$ but not path-length measures. However, the greater reliability of turning responses was not matched by an increase in accuracy. Instead, turning responses were actually less accurate than in experiment 1 (angular error, $F_{1,205}=35.19, p<0.01$; absolute angle, $F_{2,205}=47.38, p<0.01$ ) and characterized by overturning rather than underturning. Participants in experiment 3 tended to overturn the angle with a mean response of $19.9^{\circ}\left(\mathrm{SD}=27.1^{\circ}\right)$ versus experiment 1 where participants underturned the angle with a mean response of $-7.1^{\circ}$ $(\mathrm{SD}=35.9)$. However, performance was not significantly different for any of the length measures.

In addition, there were differences in how participants responded to the three triangles across experiments (Experiment $\times$ Angle $A$ : path length, $F_{2,42}=7.02, p<0.01$; angular error, $F_{5,205}=26.93, p<0.01 ;$ absolute angle, $\left.F_{5,205}=10.09, p<0.01\right)$. In both experiments 1 and 3, participants tended to overturn for small test angles (eg Angle $A=60^{\circ}$ ) and underturn for large test angles (eg Angle $A=120^{\circ}$ ). In experiment 1 , this trend was globally shifted to underturning, whereas in experiment 3 , it was shifted toward overturning. A similar trend was observed for path length: participants tended to overshoot home for the triangle with the smallest angle $A$ and undershoot for the triangle with the largest angle $A$. A final result of this cross experiment comparison is an Experiment $\times$ Gender interaction (angular error, $F_{3,205}=13.14$, $p<0.01$, absolute angle, $F_{3,205}=17.84, p<0.01$ ) confirming that women turned more than men in the first experiment and less in the third. In both cases, these responses resulted in more accurate turn estimates by women than men.

In sum, performing the homing task by active walking yielded a qualitatively different pattern of results from joystick steering with visual information alone. Participants were significantly more consistent (if not more accurate), exhibited a pattern of overturning rather than underturning, and responded similarly whether or not optic flow was available. These results strongly suggest that participants can perform path integration from optic flow when necessary, but normally rely on the body senses available during active walking.

\section{General discussion}

Let us review the questions posed at the beginning of this paper and examine several additional issues raised by the results.

Can path integration be performed from optic flow alone, without specific training?

On the basis of the results from experiments 1 and 2, it can be concluded that optic flow provides sufficient information to perform path integration with an accuracy comparable to previous data (Loomis et al 1993; Péruch et al 1997). We found that homing is more accurate in a richly textured environment containing optic flow (arena B) than it is with less visual information for translation (arena W) or rotation (arena F), or with minimal optic flow (arena N). The fact that men performed randomly when texture was minimized (arena $\mathrm{N}$ ) in experiment 2 confirmed that they relied on optic flow for path integration, rather than the visual information from the target poles (eg static information or target expansion).

This finding is complicated by insensitivity to triangle shape in experiment 1 . The tendency to produce stereotyped responses across the triangle set (consistent with Loomis et al 1993 and Péruch et al 1997) indicates that homing was not entirely dependent on sensory information, but may also have been biased toward an equilateral triangle.

Does optic flow information for translation and rotation differentially affect behavior?

Homing performance is, to some extent, differentially influenced by optic flow information for observer translation and rotation. In experiment 1 , the absence of texture on the walls (arena F), which reduced the rotational flow, significantly reduced turning accuracy. Reciprocally, the absence of texture on the floor (arena W), which 
reduced the translational flow, significantly increased the variability in path length. These results support the hypothesis that translational and rotational flow differentially affect homing behavior. This conclusion is reinforced by data from experiment 2, in which motion parallax from an array of posts (arena P) provided information about translation but reduced the area of flow specifying rotation. Men showed accurate path lengths, but less accurate angles, than in the fully textured arena (arena B). Taken together, these results indicate that optic flow can be used for path integration over distances and turns - at least when it is the only information available.

What are the relative contributions of information from optic flow and the body senses to path integration?

During active walking, however, we find that information about self-motion from the body senses dominates homing performance. First, accuracy in experiment 3 was highly similar whether or not optic flow was available (arenas B and N), indicating a reliance on other information. Second, response variability was greatly reduced in comparison to experiments 1 and 2 with vision alone. Third, although participants in experiment 3 were no more accurate than in the previous experiments, their errors were qualitatively different, exhibiting overturning rather than underturning in the final response angle. This leads us to conclude that subjects normally rely on the body senses for path integration and homing, when they are available during active walking.

This conclusion must be tempered by the fact that the HMD has a limited FOV (60 deg horizontal $\times 40$ deg vertical). It is possible that such a restricted FOV reduced the influence of optic flow relative to body senses during path integration. One way to test this would be to manipulate the FOV during triangle completion under natural open-field conditions. On the other hand, given that we observed differential performance in experiments 1 and 2 depending on the texture in the environment, it appears that optic flow can be used for path integration even with our limited FOV. Moreover, there is evidence from Rieser et al (1992) that limited FOV may not reduce spatial updating performance by observers with normal vision. Rieser et al (1992) compared the spatial knowledge of people with normal vision to those with one of two visual impairments: visual acuity loss or reduced visual field size. The group who lost visual field size early in life performed significantly poorer than the other groups when asked to judge the location of landmarks in a familiar environment. Rieser et al (1992) concluded from this that a broad visual field is important for learning a mapping between motion and visual information but, once established, is not necessarily relied on for this type of task. In line with these developmental data, Péruch et al (1997) found no significant effects of varying the geometrical FOV (40 deg to $80 \mathrm{deg}$, with a fixed actual FOV of $45 \mathrm{deg}$ ) on homing from visual information.

Are there gender differences in performance?

Three types of gender differences were observed in the present experiments: differences in response variability, differences in dependence on optic flow, and differences in the final response angle. The first two differences were observed only in experiments with vision alone. In experiment 1, we found greater variability in women's than in men's responses, for both path length and turn angle. In experiment 2, our women subjects were more variable than men and showed a greatly reduced arena effect. This indicates that they did not primarily depend on optic flow but may have relied on a timing strategy or static information from target poles to do the homing task. However, this result needs to be interpreted with caution owing to the high attrition rate for women in experiment 2 from simulator sickness. It seems likely that sensory conflict in the joystick task may have led to a higher incidence of simulator sickness in those women who relied on optic flow, and hence the women who completed the experiment may have been less visually dependent. The third gender effect, however, is more stable since it was observed across experiments 1 and 3 . 
Women turned farther than men in experiment 1 and less than men in experiment 3, but in both cases this resulted in more accurate turns.

These findings lead to mixed conclusions regarding gender differences. Whatever differences there may be in path-integration strategies, they do not appear to provide a clear advantage one way or the other. This is consistent with previous orientation and navigation research, in which, depending on the task requirements, both male and female advantages have been demonstrated (Galea and Kimura 1993; Holding and Holding 1989; Moffat et al 1998).

\section{Future research}

In the present study, we examined the information used in path integration by removing or adding sources of information. In the first two experiments, the information for selfmotion was purely visual, and the body senses were inconsistent, signaling no self-motion. In the third experiment, information for self-motion was provided by the body senses alone or in combination with vision. A more subtle way to investigate this question is to dissociate optic flow from the body senses during active walking by manipulating the visual gain in the virtual environment (eg for every $1 \mathrm{~m}$ walked, the virtual environment would translate $1.2 \mathrm{~m}$ ). In this manner, we can determine whether participants are influenced by optic flow as well as by the body senses in an active homing task.

In sum, the present results indicate that optic flow can be used to perform path integration. However, it appears that people normally rely on proprioceptive, vestibular, or efferent information during active walking.

Acknowledgements. This research was conducted with funding from a National Science Foundation Learning and Intelligent Systems grant (Grant ID: NSF LIS IRI-9720327). We would like to thank Dr Leslie Kaelbling, a primary investigator on the grant, for her guidance and support during the conceptualization and experimental phases of this project. Her encouragement, especially as the design of this project evolved under the pressures of equipment problems, was incredibly important. Second, we would like to thank Brent Shields, Theo Van Der Zee, and Don Tulanon for their assistance running subjects for these experiments.

\section{References}

Bakker N H, Werkhoven P J, Passenier P O, 1999 "The effects of proprioceptive and visual feedback on geographical orientation in virtual environments" Presence 836 - 53

Batschelet E, 1981 Circular Statistics in Biology (New York: Academic Press)

Berthoz A, Israël I, Georges-Francois P, Grasso R, Toshihiro T, 1995 "Spatial memory of body linear displacement: what is being stored?" Science $26995-98$

Bremmer F, Lappe M, 1999 "The use of optical velocities for distance discrimination and reproduction during visually simulated self motion” Experimental Brain Research $12733-42$

Chance S S, Gaunet F, Beall A C, Loomis J M, 1998 "Locomotion mode affects the updating of objects encountered during travel: the contribution of vestibular and proprioceptive inputs to path integration" Presence $7168-178$

Collett T S, Chameron S, Schatz B, Graham P, Beugnon G, 1999 "Acquisition of routes in ants", in Proceedings of the 10th International Conference on Perception and Action, Edinburgh, Scotland (Mahwah, NJ: Lawrence Erlbaum Associates) p. 67

Elliott D, 1986 "Continuous visual information may be important after all: a failure to replicate Thomson (1983)" Journal of Experimental Psychology: Human Perception and Performance $12388-391$

Esch H E, Burns J E, 1996 "Distance estimation by foraging honeybees" Journal of Experimental Biology $199155-162$

Galea L A M, Kimura D, 1993 "Sex differences in route-learning" Personality and Individual Differences $1453-65$

Gallistel C R, 1990 The Organization of Learning (Cambridge, MA: MIT Press)

Gibson J J, 1950 Perception of the Visual World (Boston, MA: Houghton Mifflin)

Glasauer S, Amorim M-A, Vitte E, Berthoz A, 1994 "Goal-directed linear locomotion in normal and labyrinthine-defective subjects" Experimental Brain Research $20311-23$

Holding C S, Holding D H, 1989 "Acquisition of route network knowledge by males and females" Journal of General Psychology 116 29-41 
Hye Young Park A, Hu S, 1999 "Gender differences in motion sickness history and susceptibility to optokinetic rotation-induced motion sickness" Aviation, Space, and Environmental Medicine $701077-1080$

Israël I, Chapuis N, Glasauer S, Charade O, Berthoz A, 1993 "Estimation of passive horizontal linear whole-body displacement in humans" Journal of Neurophysiology 70 1270-1273

Israël I, Sievering D, Koenig E, 1995 "Self-rotation estimate about the vertical axis" Acta OtoLaryngologica (Stockholm) $1153-8$

Ivanenko Y, Grasso R, Israël I, Berthoz A, 1997 "Spatial orientation in humans: Perception of angular whole-body displacements in two-dimensional trajectories" Experimental Brain Research $117419-427$

Jokerst M, Gatto M, Fazio R, Gianaros P J, Stern R M, Koch K L, 1999 "Effects of gender of subjects and experimenter on susceptibility to motion sickness" Aviation, Space, and Environmental Medicine $70962-965$

Klatzky R L, Loomis J M, Golledge R G, 1997 "Encoding spatial representations through nonvisually guided locomotion: Tests of human path integration", in The Psychology of Learning and Motivation Ed. D Medin (San Diego, CA: Academic Press) pp 41-84

Loomis J M, Klatzky R L, Golledge R G, Cicinelli J G, Pellegrino J W, Fry P A, 1993 "Nonvisual navigation by blind and sighted: assessment of path integration ability" Journal of Experimental Psychology: General $12273-91$

Loomis J M, Klatzky R L, Golledge R G, Philbeck J W, 1999 "Human navigation by path integration", in Wayfinding: Cognitive Mapping and Spatial Behavior Ed. R G Golledge (Baltimore, MD: Johns Hopkins University Press) pp 125-151

Moffat S D, Hampson E, Hatzipantelis M, 1998 "Navigation in a 'virtual' maze: sex differences and correlation with psychometric measures of spatial ability in humans" Evolution and Human Behavior $1973-87$

Péruch P, May M, Wartenberg F, 1997 "Homing in virtual environments: Effects of field of view and path layout" Perception $26301-311$

Riecke B E, Veen H A H C van, Bülthoff H H, 2000 "Visual homing is possible without landmarks", Technical Report No 82, Max Plank Institute, Tübingen, Germany, pp $1-29$

Rieser J J, 1989 "Access to knowledge of spatial structure at novel points of observation" Journal of Experimental Psychology: Learning, Memory, and Cognition $151157-1165$

Rieser J J, Guth D A, Hill E W, 1986 "Sensitivity to perspective structure while walking without vision" Perception $15173-188$

Rieser J J, Hill E W, Talor C R, Bradfield A, Rosen S, 1992 "Visual experience, visual field size, and the development of nonvisual sensitivity to the spatial structure of outdoor neighborhoods explored by walking” Journal of Experimental Psychology: General 121 210-221

Ronacher B, Wehner R, 1995 "Desert ants Cataglyphis fortis use self-induced optic flow to measure distances traveled" Journal of Computational Physiology A 177 21-27

Schiff W, Detwiler M L, 1979 "Information used in judging impending collision" Perception 8 647-658

Schiff W, Oldak R, 1990 "Accuracy of judging time to arrival: Effects of modality, trajectory, and gender" Journal of Experimental Psychology: Human Perception and Performance 16303 -316

Sholl M J, 1989 "The relation between horizontality and rod-and-frame and vestibular navigational performance" Journal of Experimental Psychology: Learning, Memory, and Cognition 15 110-125

Srinivasan M V, Zhang S W, Bidwell N J, 1997 "Visually mediated odometry in honeybees" Journal of Experimental Biology $2002513-2522$

Srinivasan M V, Zhang S W, Lehrer M, Collett T S, 1996 "Honeybee navigation en route to the goal: visual flight control and odometry" Journal of Experimental Biology 199 237-244

Steenhuis R E, Goodale M A, 1988 "The effects of time and distance on accuracy of targetdirected locomotion: does an accurate short-term memory for spatial location exist?" Journal of Motor Behavior $20399-415$

Thomson J A, 1980 "How do we use visual information to control locomotion?" Trends in Neurosciences $3247-250$

Thomson J A, 1983 "Is continuous visual monitoring necessary in visually guided locomotion?" Journal of Experimental Psychology: Human Perception and Performance 9 427-443

Warren W H, 1995 "Self-motion: Visual perception and visual control", in Perception of Space and Motion Handbook of Perception and Cognition Eds W Epstein, S Rogers (San Diego, CA: Academic Press) pp $263-325$

Yoo Y H, 2000 "Prediction and quantification of individual differences in susceptibility to simulator sickness in fixed-base simulators" Dissertation Abstracts International: Section B 603495 